\title{
Da música à crioulização: uma estória de conversão
}

\section{Wilson Trajano Filho}

\section{(2) OpenEdition}

Journals

\section{Edição electrónica}

URL: http://journals.openedition.org/aa/2622

DOI: 10.4000/aa.2622

ISSN: 2357-738X

\section{Editora}

Programa de Pós-Graduação em Antropologia Social (UnB)

\section{Edição impressa}

Data de publição: 1 dezembro 2016

Paginação: 205-266

ISSN: 0102-4302

\section{Refêrencia eletrónica}

Wilson Trajano Filho, «Da música à crioulização: uma estória de conversão», Anuário Antropológico [Online], v.41 n.2 | 2016, posto online no dia 15 junho 2018, consultado o 28 abril 2021. URL: http:// journals.openedition.org/aa/2622 ; DOl: https://doi.org/10.4000/aa.2622

\section{(c) (i) () $\Theta$}

Anuário Antropológico is licensed under a Creative Commons Atribuição-Uso Não-Comercial-Proibição de realização de Obras Derivadas 4.0 International. 


\title{
Da música à crioulização: uma estória de conversão
}

\author{
Wilson Trajano Filho
}

$\mathrm{UnB}$

\section{Advertência}

Quem me leu Dilemas, projetos e questóes: reflexóes quase musicais de um antropólogo convertido (Trajano Filho, 2011a: 291) talvez reconheça estas palavras do texto: "assim, a história de meus vínculos com a antropologia é um pouco também a dos meus desvínculos com a música”.

Referia-me ao nevoento caminho por mim percorrido nos últimos 41 anos. Tratando-se agora de escrever este memorial para professor titular, achei que a parte relativa aos 23 anos como docente na Universidade de Brasília (UnB), se for decotada de algumas circunstâncias, anedotas, descriçóes e reflexões, pode dar uma narração seguida que talvez interesse, apesar da forma híbrida. Não houve pachorra de a redigir à maneira daquela outra - nem pachorra, nem habilidade. Vai como está, mas desbastada e estreita, conservando só o que liga o mesmo assunto. $\mathrm{O}$ resto aparecerá um dia, se aparecer algum dia. Só não sei dizer sob que forma.

\section{Introduçáo}

Apesar de aparentemente consolidado como gênero acadêmico, o memorial (de formação ou descritivo) ainda provoca desconforto em alguns cantos da antropologia, num dos quais eu me encontro. Digo isto depois de ler alguns. A hibridez do gênero, entre a autobiografia autocentrada e o comentário burocrático do curriculum vitae, provoca, se não um mal-estar generalizado, uma medida de incômodo e apreensão. De fato, trata-se de uma forma textual que engloba os contrários, e me parece estar aí a razão de tanta inquietação.

Deixe-me ir com mais vagar nisto. Por um lado, não parece caber dúvida de que o memorial acadêmico é um documento de natureza autobiográfica em que se descrevem, analisam, criticam e avaliam acontecimentos e vivências oriundos da trajetória intelectual, científica ou artística do autor. Trata-se de uma espécie de texto relativamente recente em nossa cultura acadêmica, datando grosseiramente de meados dos anos de 1930, momento fundacional na história da universidade brasileira. Pode ou não ter a forma de uma narraçáo seguida, sendo, mesmo disfarçadamente, uma espécie de diário, como Ele já advertia, 
em que se contam experiências e realizaçóes. São características do memorial acadêmico a celebração de si e a reflexão sobre o caminho percorrido, escritas em primeira pessoa, especialmente voltadas para os fatos que fazem do autor alguém memorável (na sua área de atuação). Por outro lado, há uma longa tradição de literatura memorialista que tem como gêneros mais consolidados, em sua vertente erudita, a elegia e o panegírico, destacando-se, em versôes populares, a louvação e a homenagem. Seja em uma ou em outra dimensão, o que se tem são formas escritas e orais em que se homenageia sob a forma de lamento e se dá expressão à dor e ao pesar, num tom solene e triste, causados pela perda (interna e individual) de uma terceira pessoa que morreu recentemente.

Apesar das diferenças agudas no tom, no estilo e na forma, o memorial acadêmico e a literatura memorialista compartilham um traço diferenciado. Em sua desconcertante generalidade, os dois gêneros descrevem ou narram um trajeto, quase sempre dando mais destaque às suas estaçôes finais. É justamente nisto que se encontra a ambivalência que desassossega: o memorial tanto pode focalizar e celebrar o apogeu da energia vital como pode lamentar, louvar e fazer o elogio solene ou o tributo a quem, indo além do cume, já fez o misterioso transbordo e agora se derrama transmigrado na terceira margem do rio. Estamos perante o já mencionado englobamento ou fusão de contrários, no caso, de Tânatos e Eros.

O passado de músico demanda do antropólogo algum cuidado e provimento, pois uma sutil inclinação, que me passa quase desapercebida, delicadamente me leva a olhar esse meu esforço de memorialista de circunstância com as lentes do réquiem ou da louvação. Como forma de expressão, não há competição possível entre a celebração às vezes dolorosa e às vezes sublime das Missas de Réquiem de Mozart, Verdi e Fauré e os textos descritivo-analíticos dos memoriais acadêmicos, até mesmo dos mais notáveis cientistas ou intelectuais. Estes perdem sempre, apesar de sua racionalidade e eventual elegância. Mas a boa dose de realismo que tem me acompanhado pela vida, o amor pela radicalização da racionalidade e a resignada renúncia à expressão fácil me conduzem à busca do caminho do meio: algo entre o puro jorro expressivo que arrebata a alma e a transparência límpida, seca e dura da forma e da razão.

Náo se trata de um percurso fácil nem de uma receita simples de seguir ou imitar. Náo consigo encontrar por mim mesmo o caminho do meio que constitui uma realidade singular. Não quero, porém, a fórmula pronta do currículo burocraticamente comentado. Entáo vou buscar socorro no melhor da minha tradição, pelo menos como uma forma de enquadrar o trajeto a ser narrado e comentado. Não poderia achar solo mais promissor do que o reino da linguagem - a morada da razáo e da expressão - e de seus grandes homens. Pois é na 
prática imitativa do herói maior da língua que espero encontrar uma situação social, um naco de realidade e experiência, que constitui um fluir vital, sui generis e, como Ele também costumava dizer, decotada de algumas circunstâncias, anedotas, descriçóes e reflexóes.

\section{Formaçáo}

Faz 35 anos que entrei definitivamente para a antropologia. O que me lembrou essa data foi, estando a beber café e a matutar sobre meus afazeres, o pregão de um vendedor de pamonhas: "pamonhas, pamonhas! De doce e de sal!"1 Costumo ouvi-lo outras tardes, mas desta vez trouxe-me à memória o dia do desembarque, quando cheguei transformado à minha Brasília, à minha $\mathrm{UnB}$ e, de volta, à minha língua natural. Não era o mesmo pregão que ouvira há 35 anos, em 1981, e certamente não era a mesma boca.

No início de 1981, depois de seis anos no curso de composição e regência da UnB, um ano como professor da Escola de Música de Brasília e um ano como docente na habilitação em música do curso de educação artística da Universidade Federal da Paraíba (UFPB), retornei a Brasília para começar uma nova fase na vida: cursar o mestrado em antropologia.

Por que deixar a música pela antropologia? Por que abandonar uma promissora carreira de compositor e docente universitário iniciada aos 26 anos, com dois trabalhos publicados (uma raridade no campo musical daquela época), para iniciar uma nova formaçáo?² Por que trocar um emprego estável, com uma remuneraçáo digna, por uma bolsa modesta e um futuro incerto? Por que comprometer a renda familiar e depender em grande medida do trabalho e da generosidade da companheira amada no sustento e gerenciamento da casa, com uma criança de 3 anos e outra por chegar? E por que a antropologia, especificamente: por que não fazer uma pós-graduação na música ou em outra área qualquer das humanidades?

Para algumas dessas perguntas, mal posso esboçar um arremedo rascunhado de resposta. Para outras, tenho a dita na ponta da língua. Que vá, então, das diretas às indiretas, do certamente sabido ao francamente devaneado, passando por toda uma gama de especulaçóes com graus variados de razoabilidade.

Que fosse do meu conhecimento, não havia no Brasil da época nenhuma pós-graduação em música com ênfase nas minhas áreas de interesse: composição e análise musical. Assim, qualquer fantasia de envolvimento com os estudos pós-graduados na minha área de formação original implicava deixar o país. O problema era que a forma mais viável dessa escolha - a bolsa à época chamada de PICD, com a qual eu manteria o vínculo empregatício com a UFPB - me obrigava a esperar numa longa fila formada pelo conjunto nada pequeno de jovens 
docentes que foram para a Paraíba ávidos por uma formação pós-graduada no exterior. O sentimento de urgência que me assolava não deixava tranquilo, num aguardar passivo que poderia tardar imenso, o zen-budista (em versão libanesa) que habitava em mim.

A juventude, com sua inerente boa dose de irresponsabilidade e a certeza desmedida da generosidade do amor, parece-me, no presente, explicar o desprendimento material, a disposição para uma eventual dependência econômica e o despreocupado olhar para o futuro que não ligava nenhuma à estabilidade e à previsão. Estas seriam coisas de gente velha, como eu agora.

Acho que, na época, o retorno a Brasília e o engajamento com a antropologia não significavam abandono, nem da música nem do devaneio com uma carreira musical. Seriam, quando muito, um ponto de inflexão para um recomeçar revigorado e mais radical na experimentação com a linguagem musical. Eu deixara Brasília no início de 1980 para dar aulas na UFPB porque precisava de tempo para compor. Na Escola de Música de Brasília, passava as minhas horas em entediantes aulas de teoria e solfejo para iniciantes ou, quando muito, de contraponto e harmonia para instrumentistas desinteressados nesses assuntos. O tempo para composiçáo era escasso e os projetos se acumulavam vertiginosamente sem que eu pudesse dar concreção às ideias sob a forma de peças musicais.

Minha breve carreira era relativamente exitosa no que havia de mais difícil: ter as obras executadas. Pouco antes de ir para João Pessoa, em final de 1979, minha primeira peça sinfônica foi executada em três ou quatro ocasióes pela Orquestra Sinfônica do Teatro Nacional porque o seu regente titular, maestro Claudio Santoro, um dos meus professores de composição, admirava o meu trabalho, que considerava ser o de um iconoclasta. Pela mesma época também foram tocadas algumas peças de câmara que tiveram uma crítica bastante favorável. Mas, se não tinha grandes dificuldades em mobilizar os colegas para executar meus trabalhos, o tempo para compor era mais do que escasso vis-à-vis o jorro de ideias musicais que inundavam a minha imaginação.

Foi nessa circunstância que apareceu o convite para me candidatar a uma vaga na UFPB, onde eu teria uma carga docente de apenas 12 horas semanais, tendo o restante de meu tempo livre para me dedicar à composição. O salário era melhor do que eu ganhava em Brasília, e o custo de vida mais barato da cidade mais do que compensava uma eventual perda de renda de minha companheira de sempre. Fomos então de mala e cuia, como se dizia na época, para João Pessoa, sem perceber que a falta de um ambiente que engatilhasse minha imaginação musical acabaria por produzir em minh'alma uma frigidez criativa da qual ainda sinto o arrepio avassalador. 
O ano de 1980 foi para mim um tempo de aridez musical. O Departamento de Educação Artística da UFPB não tinha sequer um piano para as aulas e para o trabalho de composição. As aulas eram dadas num piano alugado pela professora da disciplina, que, obviamente, tinha o monopólio de seu uso. Meu manancial criativo, por uma razão que mal posso imaginar, secou de repente. Mas se a música padecia num deserto, a vida política era mais do que efervescente. O fim do regime militar se prenunciava, as greves docentes, que mais tarde se tornaram o nosso mais desgastante vício, aconteciam com uma regularidade impressionante, e os professores da música eram chamados a participar dos precários e improvisados shows de mobilizaçấo. De música, a única coisa que fiz foi tocar contrabaixo ou violáo e cantar num quarteto vocal em tristes e vazios espetáculos para angariar recursos para mais uma paralisação.

Foi a vida estéril nesse ambiente que me fez decidir sair para fazer uma pósgraduação no Brasil, sem entrar na longa fila do PICD — isto depois de tentar sem êxito voltar para a Escola de Música. Uma legislação da época proibia a contratação de gente com um longo bacharelado em composição e regência para dar aulas de matérias típicas desse campo. Em seu lugar, garantia uma reserva de mercado para os licenciados em educação artística. A isto também se chamava pedagogia.

Não foi difícil escolher a área em que me aventuraria. Excluídas de saída estavam todas aquelas próximas das ciências duras, em que imperava a linguagem da matemática, táo desconhecida para mim. Sem física, química, biologia e engenharias como opçóes, restavam-me as humanidades. E, entre estas, a paixão fez sua escolha.

Que seja bem entendido: a mulher que tem me acompanhado todos esses anos havia feito sua graduação em antropologia. E nosso viver junto implicava trocas variadas: de fluidos e afetos, de amigos e de ideias. Em nossa biblioteca comum havia exemplares da produçáo antropológica que muitas vezes eu me esforçava por ler, entender e me ilustrar. Lembro-me com especial clareza de um artigo de Lévi-Strauss (1978) chamado "Mito e música", publicado na coletânea Mito e significado. Li esse pequeno texto mais de uma vez e, por um desses mistérios de difícil explicação, fui assaltado por um fascínio inversamente proporcional ao entendimento que dele eu procurava ter. ${ }^{3}$

Outros textos e outras palavras mágicas caras ao curso da amada reverberavam em meu espírito de tal modo que, durante a graduaçáo na UnB, cursei a disciplina Introdução à Antropologia, ministrada pela professora Eurípedes Cunha Dias. Esperava muita especulação e muito devaneio sobre morfologia, estruturas e sistemas - ideias particularmente caras à música radicalmente experimental e vigorosamente antiexpressiva que àquela altura eu vivenciava 
de modo ambivalente - , mas encontrei uma reflexáo, para mim um tanto complicada, sobre o conceito antropológico de cultura e uma aventura (é essa mesma a palavra que busco, com seus ingredientes de fantasia e imaginação) sobre o desenvolvimento das formas de organização social: a revolução neolítica, a domesticação das plantas e dos animais e os primórdios da sedentarização e da urbanização. Assim, juntando a paixão dos afetos com a do intelecto, fiz um pedido de dupla opção, pensando em fazer uma segunda graduação, depois de minha formatura na música.

No entanto, os percalços corriqueiros da vida, o filho que chegou inesperado, a boa ambição de construir uma carreira musical de sucesso e a certeza da reciprocidade afetiva fizeram com que eu abandonasse esse projeto-devaneio por algum tempo. Deixei a vida me levar até que a aridez musical vivida por mim em 1980 viesse me lembrar das possibilidades do casamento disciplinar entre música e antropologia. E assim foi que, ao procurar uma pós-graduação que me tirasse do exílio paraibano, fui conduzido sem muito pensar para a antropologia.

O mestrado na Universidade de Brasília foi um tempo de descobertas e encontros. Apesar das imensas dificuldades no aprendizado da nova linguagem e de seu jargão peculiar nos primeiros meses, rapidamente encontrei uma nova vocaçáo. Naquele início dos anos 1980, o estruturalismo francês ainda exercia influência na antropologia que se fazia em Brasília, complementado por uma forte orientação sistêmica de natureza geral. Isto se revelava até mesmo nos nomes das disciplinas, como Análise Estruturalista: Sistemas Ideológicos, Análise Estruturalista: Sistemas Sociais, Análise de Sistemas Simbólicos, Sistemas Mitológicos. Como parte da formação, cursei onze disciplinas, todas elas em torno de um núcleo temático que anacronicamente eu chamaria de sistemas simbólicos. Muitas delas foram ministradas por um grupo de professores a quem devo o fato de ter me tornado antropólogo e aqui presto homenagem: Peter SilverwoodCope, Mariza Peirano, Klaas Woortmann e, um tanto deslocado desse núcleo de antropólogos, o sociólogo Fernando Correia Dias.

Foi nesse período que reencontrei o professor do Departamento de Física José de Lima Acioli, que se tornou desde então, até seu falecimento, em 2007, uma espécie de alma gêmea. Por essa época, ele se divertia fazendo cinema, e o fazia com a maestria, o humor e a liberdade típicos daqueles que não pertencem a escolas, grupelhos e movimentos. Além de me considerar tributário de seu pensamento engajado, criativo e com a pitada certa da leveza porra-louca, esse querido e saudoso amigo deu-me uma sobrevida como músico, me escolhendo como o autor das trilhas sonoras de seus filmes. Com uma delas, a do filme Cruviana, ganhei em 1982 o prêmio de melhor música no $1^{\circ}$ Festival Brasiliense 
de Cinema (e ele ganhou o prêmio de melhor filme), e com esse dinheiro financiei parte de minha pesquisa de campo de cinco meses entre músicos profissionais no Rio de Janeiro, que resultou em minha dissertação de mestrado, Músicos e música no meio da travessia.

Devo mencionar ainda a grande contribuição dada ao meu processo formativo pela professora Alcida Rita Ramos, de quem nunca fui aluno direto, mas com quem muito aprendi. Com uma generosidade extrema, Alcida me convenceu a fazer em sua companhia, como ouvinte, um curso de extensão sobre hermenêutica filosófica. Terminado o curso, durante cerca de um ano continuamos a nos encontrar regularmente aos sábados, em sua casa, para discutir as obras de Ricouer, Gadamer e Heidegger bem como as de seus comentadores. Lembro-me dessa época como um tempo de grande efervescência e de muitas descobertas.

A antropologia interpretativa, entáo lida com as lentes da hermenêutica e com as do sociólogo-antropólogo que me encantou desde a primeira leitura (sem que eu tivesse uma introdução sistemática e guiada à sua obra), Erving Goffman, foi essencial para a composição de meu trabalho de mestrado sobre a constituição do campo da música, suas tensões internas, suas formas de distinção e prestígio e seus rituais de reprodução, escrito sob a orientação da professora Mariza Peirano e defendida em meados de $1984 .{ }^{4}$

Esse trabalho se voltava para a análise dos atos de música que eram os ensaios e concertos de orquestra. Escrito sob a influência dos rituais de interação de Goffman, das abordagens performativas (com perdão da palavra, que uma década mais tarde virou jargão fácil na boca de todos os epígonos da disciplina), dos rituais e das análises do simbolismo com forte inspiração sociolinguística, Músicos e música no meio da travessia trazia consigo uma novidade que ainda hoje, passados 32 anos de sua defesa, tem algo de novidadeira: o experimentalismo da escrita, que mistura ludicamente imitaçóes canhestras de textos literários, diários de campo, roteiro cinematográfico com o texto convencional da análise antropológica, tudo escrito em primeira pessoa - algo um tanto inusitado na época -, mas sem o autocentramento egoísta e infantil que veio a caracterizar os chamados textos pós-modernos, que ganharam grande visibilidade a partir de meados da década de 1980. Atribuo a novidade textual ao meu contato com a hermenêutica filosófica e ao meu passado, então recente, de compositor obcecado com a experimentação de formas e texturas sonoras.

Em memoriais acadêmicos, que refletem sobre trajetórias intelectuais, não é de todo um despropósito reivindicar pioneirismo e originalidade. Experimentos com o texto antropológico estavam sendo produzidos nos Estados Unidos, num contexto geral de radicalizaçáo da antropologia simbólica ou interpretativa, cujos 
principais proponentes eram Geertz (1973) e Schneider (1968, 1984), e de crítica ao realismo etnográfico. ${ }^{5}$ Porém, com raras e, no meu entender, pouco louváveis exceçôes (Dwyer, 1982; Tedlock, 1983), tratava-se de tímidas experiências. Num tempo em que não havia internet e num país vivendo uma séria crise econômica, onde comprar um livro importado exigia uma verdadeira maratona por instituiçóes bancárias para efetuar o pagamento em divisas ou se submeter a mais uma das jabuticabas pátrias, o famigerado "dólar-livro", eu tinha poucas informações sobre a gestação do que viria a ser chamado de antropologia pós-moderna em 1983, quando comecei a escrever minha dissertação. ${ }^{6}$ O que ela tem de novidade se deve, para o bem ou para o mal, à pulsão que tem me acompanhado pela vida de experimentar com novas formas e novos jeitos de fazer as coisas, e náo à cópia dos tímidos experimentos do norte. Por isso, acho que meu trabalho de mestrado aportou uma contribuição não só para a antropologia da música e para a análise dos rituais, mas também, e especialmente, para alargar os horizontes de possibilidades da escrita etnográfica. ${ }^{7}$

A experimentação textual é uma coisa que me move e me provoca. De certa maneira, eu a persigo em muitos de meus textos, embora ultimamente eu esteja desenvolvendo a esse respeito uma atitude mais artesanal e menos ousada do que a de meu primeiro trabalho. Sou muito atento aos limites do texto antropológico, e mais ainda aos da textualidade monofônica tout court. Porém, me interessa muito pouco elaborar sobre isto no modo reflexivo - um solo fértil para imposturas de toda a ordem, inclusive a dos pós-modernos, que critiquei com acidez em Trajano Filho (1988, 2011a). Experimentar é uma aventura da prática, um arriscar sem proteção, um estar sempre perante os perigos e as ameaças das tentativas falhadas, e não um assunto para reflexão segura ou para a vicária aventura que tudo faz menos aventurar.

Depois desse trabalho com os músicos profissionais, analisando os variados atos de música por meio dos quais o grupo se inventa e se reproduz, nunca mais retomei o tema como sujeito primeiro da reflexão ou como ator principal. Acredito, contudo, que nele se encontra o germe de uma inquietação que mais tarde veio a ter grande importância na minha reflexão madura: o interesse na cultura popular. De algum modo posso dizer que fui dos músicos à música, e desta às variadas formas de expressão da vida que chamamos de cultura popular (ver mais adiante). Em todo esse trajeto, fui guiado pelo princípio segundo o qual as coisas - categorias substantivas, como grupos sociais (músicos, atores, médicos, sacerdotes etc.) e campos de fenômenos (religião, política, arte etc.) — só existem em atos. Nisto, a minha fonte de inspiração primeira veio das leituras de Austin (1962) e Searle (1969), sobre os atos de fala, e de Goffman (1967, 1974), 
sobre os processos de gerenciamento das impressóes que constroem (e destroem) as faces, mais tarde complementadas pela literatura sobre a dimensão pragmática da linguagem (Agha, 2007; Brown \& Levinson, 1978; Gumperz, 1982; Gumperz \& Hymes, 1972; Hymes, 1964, 1971, 1974; Silverstein, 1976).

Terminado o mestrado, engatei logo a formação doutoral. Esta, fui fazer na Universidade da Pensilvânia, nos Estados Unidos. Não tenho uma explicação convincente e bem-acabada para essa escolha. Algumas pistas me são caras. O Departamento de Antropologia daquela universidade era a instituição em que lecionava Goffman, e eu imaginava que gostaria muito de estudar com ele. O mesmo departamento tinha um programa ou linha de pesquisa chamada Culture, Language and Society, que se voltava para as análises das interfaces entre essas três dimensóes da vida coletiva, o que então exercia em mim um grande fascínio. Além disto, em outros departamentos da universidade, lecionavam pessoas que de uma misteriosa forma me atraíam intelectualmente, destacando-se as figuras de Dell Hymes (com quem fiz um curso de etnografia da fala) e Labov (com quem nunca estudei). Acho (é essa mesma a palavra) que foi por isso que me candidatei ao doutorado na Pensilvânia.

Nem tudo correu conforme eu devaneava em Brasília. Descobri que Goffman havia falecido cerca de um ano antes de eu receber a aceitação da universidade. Ainda bem que eu tinha uma segunda opção, a Universidade da Virgínia, escolhida basicamente por causa da presença de Victor Turner no seu departamento de antropologia. Mas, pela mesma época, vim saber que o decano da antropologia dos rituais também havia falecido. Assim, fui para Filadélfia apostando que o programa Language, Culture and Society atenderia às minhas expectativas de complementação da formação antropológica.

Cheguei à Pensilvânia em agosto de 1984 com a companheira da vida e dois filhos pequenos, poucos meses depois de concluir o mestrado. A primeira impressão do departamento não foi nada boa para o "iconoclasta ambicioso e otimista" que acabara de escrever um texto bastante experimental, porém bem avaliado pelos professores e colegas no Brasil. O departamento pareceu-me envelhecido. Tinha como figuras seniores a fina flor da antropologia cognitiva das décadas anteriores, mas que em meados dos anos 1980 tinham um jeitão anacrônico: Ward Goodenough, Bill Davenport e Anthony Wallace. Além disto, ali se cultivava o que à época me parecia outro insistente anacronismo: a antropologia dos quatro campos. De início, foi um verdadeiro suplício ter que fazer as disciplinas da arqueologia e da antropologia biológica. Elas pareceram chatas e sem sentido, mas com o passar do tempo fui me encantando com a fértil imaginação desses colegas antropólogos que reconstroem processos incrivelmente complexos e 
longos a partir de pequenos fragmentos de informações. Imaginativos, porém bem ancorados no mundo dos sentidos. Para alguém que ainda se pensava como músico, aquilo era encantador. Por outro lado, desde logo gostei da interface com a linguística, fazendo uma cadeira com Goodenough chamada Culture, Language, and Society e uma dirigida por Dell Hymes chamada Ethnography of Speaking.

Mas foi o contato com professores que eu até então desconhecia que alargou meus horizontes e mudou definitivamente o rumo de minha carreira. Com Brian Spooner, um inglês formado em Oxford, com longa experiência de pesquisa no Afeganistão e Paquistão, fiz a disciplina Antropologia do Desenvolvimento e um curso tutorial sobre identidade social. Estou certo de que minhas discussóes com Brian tiveram um papel importante na opção de fazer pesquisa fora do Brasil, isto é, de ampliar empiricamente meu horizonte de interesses numa época em que mesmo os que faziam pesquisas fora do país, normalmente as faziam nos países em que estudavam, o que era também uma forma de fazer antropologia em casa. Com Igor Kopytoff, uma ave rara na antropologia (Trajano Filho, 2012a), tive a minha introdução à etnologia africana. ${ }^{9}$ Fiz com ele um curso de antropologia da África mais dois outros (tutoriais) sobre religião e simbolismo naquele continente. Estes cursos aconteceram num período de efervescência em minha vida pessoal e intelectual. Lembro-me de ter lido a famosa introdução que ele havia escrito para o livro sobre as fronteiras africanas em uma versão anterior à que foi publicada (Kopytoff, 1987). Também foi numa versão saída de uma impressora matricial (são esses detalhes que me fazem constatar que sou mesmo do tempo do onça), lida para o seminário de Antropologia Econômica, dirigido pelo jovem professor Arjun Appadurai, que tive o primeiro contato com o fabuloso texto sobre a biografia cultural das coisas (Kopytoff 1986), bem como o que veio a ser a introdução do livro (Appadurai, 1986).

Passei o verão (americano) de 1986 em Brasília para ficar perto de minha mulher e meus filhos, que retornaram ao Brasil porque o valor da bolsa do CNPq não bastava para as contas americanas. Não conseguimos sobreviver na Filadélfia com os 1.180 dólares que eu recebia mensalmente. Pouco antes de viajar, recebi uma longa carta de meu amigo José Acioli dizendo que tinha acabado de filmar uma adaptação do que é, para mim, um dos mais belos contos da literatura o mágico "A terceira margem do rio", de João Guimarães Rosa. Na carta ele me contava do seu entusiasmo com o material que havia trazido de um mês de filmagens no Rio Araguaia e me convocava para escrever a música para o filme. Passei os meses de julho, agosto e setembro na seca brasiliense matando as saudades dos amores e dos amigos e assistindo, vezes sem conta, ao copiáo do 
filme e, depois, à primeira versão editada. Discuti com Acioli os trechos em que a música deveria entrar e o espírito que ela teria. Uma vez acordados, cronometrei as sequências a serem musicadas e passei a escrever os primeiros esboços. De comum acordo, decidimos que seria uma música muito simples, escrita para um trio bem brasileiro de violão, flauta e violoncelo.

Voltei à Filadélfia em setembro de 1986 com esboços da música do filme e de meu projeto de pesquisa doutoral sobre as ideias de nação elaboradas pelo Estado guineense e veiculadas nas escolas no país, especialmente no contexto das aulas e dos livros didáticos de história e geografia. Lembro-me de que tive muita dificuldade para convencer meu orientador de que aquilo poderia ter uma cara antropológica. Com seu jeito provocador, Igor me dizia que todo antropólogo devia ter a sua tribo, buscando assim me convencer a estudar os bijagós e me entusiasmar com a ideia de fazer uma boa etnografia desse grupo étnico guineense, (pouco) conhecido na literatura antropológica por sua extremada matrilinearidade. Não o fiz, mas àquela altura Christine Henry andava por aquelas belas ilhas e produziu um não menos belo volume sobre esse povo tâo exotizado no imaginário da disciplina (Henry, 1994).

Passei o restante do ano e os primeiros meses de 1987 lendo a parca literatura existente sobre a Guiné-Bissau na biblioteca da universidade, aprimorando o projeto de pesquisa e preparando os textos para apresentar em meu exame de qualificação. ${ }^{10}$ No pouco tempo livre que tinha, aprimorava os esboços trazidos do Brasil para a trilha sonora do filme do meu amigo. Com muita tristeza e frustração, eu notava então que meu ouvido interno (uma espécie de capacidade adquirida com anos de treinamento de ouvir minha imaginação musical) já não era o mesmo e que, sem acesso a um piano ou violão, eu tinha enorme dificuldade de escrever aqueles fragmentos musicais.

Sobre meu tema e local de pesquisa: a ideia de nação como projetos em competição em arenas específicas do mundo social vinha sendo gestada desde meu período de formação no mestrado. Era um desses pratos de longa preparação e lento cozimento que fazem a boca salivar. Enquanto completava o treinamento na Filadélfia, eu ia afinando a ideia e ganhando apetite para estudar etnograficamente processos de construção nacional. Certeza eu tinha de que queria me afastar da realidade brasileira na pesquisa de maior fôlego que em breve faria. A África surgiu como a opção a ser trilhada logo depois que fiz o primeiro curso sobre etnologia africana. Um engano foi cuidadosa e gradualmente tecido no processo de escolher o local para a pesquisa sobre a construção da nação. Naquela época, eu e meu orientador achávamos que a África de expressão portuguesa seria uma escolha natural e vantajosa. Primeiro, pelo fato de serem países de idioma oficial 
português. Isto, em princípio, facilitaria minha pesquisa e faria com que eu tivesse um acesso mais imediato e profundo às entranhas da vida social. A vantagem se devia em parte à pobreza e debilidade da antiga potência colonial. Diferente dos ingleses e franceses em África, os portugueses conheciam muito mal as suas colônias, o que tornava os países recém-independentes um campo ainda pouco explorado para a investigação antropológica.

Assim, a "África portuguesa" enganosamente me pareceu uma escolha natural. ${ }^{11} \mathrm{E}$, dos países que a compunham, a Guiné-Bissau cintilava como a (única) opção. Em 1986, quando comecei a escrever meu projeto de pesquisa, o socialismo náo dogmático de Amílcar Cabral, o herói da nacionalidade guineense, ainda era largamente admirado no meio acadêmico, e a Guiné-Bissau ainda recebia uma grande leva de "pés vermelhos" que para lá se dirigiam no devaneio esperançoso de contribuir com a construção de uma sociedade justa e horizontal. ${ }^{12}$ Cabo Verde, do qual eu pouco sabia, nunca foi tido propriamente como uma sociedade africana (por muitos cabo-verdianos e por outros), o que tornava o arquipélago uma escolha pouco atrativa para quem investira muito no treinamento africanista. ${ }^{13}$ Sáo Tomé era táo diminuto e desconhecido que nem me lembro se cheguei a considerá-lo como um possível lugar de pesquisa. Angola e Moçambique, os gigantes da "África portuguesa", estavam na época assolados por sangrentas e, no caso angolano, longas guerras civis que inviabilizavam qualquer devaneio de para lá me dirigir. Não fosse isto, o nome Luanda, que provoca em mim um fascínio irresistível por sua beleza aguda e seu feminino encanto a espargir doces feromônios, teria me atraído tal como as mami watas encantam perigosamente os argonautas africanos, e eu me deixaria levar, inebriado, pelos sentidos.

Em abril de 1987, fiz meu exame de qualificação, que constava na defesa oral de um plano de pesquisa e de quatro revisóes de temas antropológicos (dois tópicos analíticos e duas áreas etnográficas). O plano de pesquisa visava analisar os projetos em competição para a nação guineense formulados por instituiçôes estatais como o aparato escolar. Seu arcabouço primário partia da ideia de que um projeto nacional é um desdobramento complexo do ato de identificação simples, cuja formulação correlaciona três categorias fundamentais: tempo, espaço e pessoa. Elas seriam, portanto, os ingredientes básicos da fórmula mais simples da identidade social (por exemplo, "eu sou guineense"). Na fórmula identitária, as ideias abstratas de tempo, espaço e pessoa se cristalizam substantivamente nos seguintes valores: história (a organização social do tempo coletivo), territorialidade (a organização do espaço sociopolítico) e cidadania (a articulação da pessoa com a totalidade da comunidade política). Eu imaginava que, se conseguisse 
compreender como o sistema educacional propóe a substantivação das categorias abstratas nos valores que lhes são correlatos, eu entraria no coração dos projetos para a nação guineense formulados no âmbito do Estado. ${ }^{14}$

Fui aprovado sem maiores contratempos. Consegui 1.000 dólares do fundo que o departamento mantinha para ajudar a custear parte da pesquisa de campo. Esse dinheiro não dava sequer para comprar a passagem para a Guiné, mas foi por mim tomado como um índice de bons presságios. Voltei ao Brasil, esperando obter mais recursos para o custoso translado para Bissau e formar uma poupança com a minguada bolsa em dólares que recebia do CNPq. ${ }^{15}$

Em Brasília, além de voltar a viver em família, terminei e gravei a música de A terceira margem e escrevi um dos meus textos antropológicos mais conhecidos e mais lidos (Trajano Filho, 1988). Tratava-se de um artigo-resenha bastante azedo, mas bem-humorado, sobre o volume que muito rapidamente se tornaria a bíblia da antropologia pós-moderna: a coletânea de Clifford e Marcus chamada Writing culture. Além de rever os principais tópicos apresentados pelos autores dos capítulos do livro, dei especial atenção ao autocentramento ingênuo dos sujeitos, que assolava, com maior ou menor intensidade, todas as contribuiçóes; aos problemas relacionados à produção da demanda pela reflexão que estão na raiz dessa virada antropológica, sem que os autores tivessem disto a menor consciência; e à obsessáo de pensar o experimento textual quase sempre conjugada com a recusa em praticá-lo. Apesar da copidescagem canhestra a que foi submetido, ainda vejo nele alguma graça, passados quase trinta anos.

Em maio ou junho de 1987, Mariza Peirano me pôs em contato com Peter Fry. Isso significou bem mais do que conhecer pessoalmente um antropólogo de respeito, uma pessoa bem-humorada e cheia de boas intençóes. Formado na ortodoxia inglesa, uma década de Brasil o ajudara a sacudir toda a poeira e retirar os ácaros que normalmente se acomodam nessas vestimentas intelectuais. Peter, àquela altura, dirigia o escritório da Fundação Ford no Rio de Janeiro. Sempre gentil e animada com o que eu estava fazendo, Mariza contou ao Peter sobre meu projeto africano e ele, segundo ela, se entusiasmou com meu devaneio de fazer antropologia fora de casa. Depois de ler o meu projeto e comentá-lo, Peter sugeriu que eu solicitasse recursos à Fundaçáo Ford. E, na quebradeira que o país vivia, especialmente no que tocava ao financiamento da pesquisa científica, um recurso da Ford, pouco que fosse, seria o "ó do borogodó". Apresentei o projeto pleiteando financiamento e pouco tempo depois recebi uma carta da fundaçáo me informando que teria o montante de 1.000 dólares à guisa de auxílio de pesquisa, mais o bilhete aéreo de ida e volta para a Guiné-Bissau. 
Pouco tempo depois, em novembro de 1987, desembarquei em Bissau, sem conhecer ninguém, sem ter onde ficar e com cerca de 4.000 dólares para passar uns 12 meses no país. Este certamente não é o lugar apropriado para refletir sobre as dificuldades práticas enfrentadas durante minha pesquisa. Vale, contudo, destacar que meu esquemático projeto logo se mostrou inviável, quando percebi a fragilidade do sistema escolar do país (cujos professores chegaram a fazer uma greve que durou nove meses, mantendo as escolas fechadas) e a inexistência de material didático (os manuais e livros de história e geografia) que eu tencionava analisar. Mantive o interesse nos processos de construção nacional, sob a forma de projetos para a nação que competem num campo de forças sociopolítico, mas fui à procura de outros sujeitos formuladores e de outros veículos de sua expressão e transmissão.

Descobri muito rapidamente que, mais do que o Estado, os sujeitos autores dos projetos nacionais eram quase todos oriundos da sociedade crioula guineense - uma formaçáo social que resultou dos encontros históricos e regulares entre agentes europeus (portugueses em sua maioria) e as variadas sociedades africanas da costa. Na realidade, a elaboração de um projeto identitário para si mesmo, como uma nação, foi parte da estratégia encontrada pelo grupo para se reproduzir num contexto em que o mundo crioulo se via ameaçado de perder a distinçáo historicamente alcançada, se dissolvendo entre os indígenas ou se subordinando completamente aos agentes colonizadores.

Eram crioulos os projetos nacionais em competição na Guiné-Bissau de meados da década de 1980. Dois desses projetos se apresentavam de maneira bem articulada e completa, tendo uma natureza institucional e um estilo normativo. Eram facilmente apreendidos sob a forma de documentos produzidos por instituiçóes do Estado e da sociedade civil.

$\mathrm{O}$ primeiro deles era o projeto de uma nação que conclamava pelo "retorno às origens”. Seu maior proponente era o herói da nação, Amílcar Cabral, um membro típico da sociedade crioula, nascido na Guiné, de pais cabo-verdianos. Em 1987, o "retorno às origens" ainda era o projeto hegemônico do partido no poder - o Partido Africano da Independência da Guiné e Cabo Verde (PAIGC) — e das instituiçôes do Estado. Por origem, Cabral se referia ao modelo das sociedades acéfalas da costa da Guiné que, segundo a melhor historiografia da região, parece ter predominado no passado pré-colonial (Barry, 1988; Brooks, 1993, 2003, 2010; Carreira, 1972; Curtin, 1975; D’Azevedo, 1962; Hair, 1997; Havik, 2004; Mark, 1985, 2002; Mouser, 1980; Niane, 1989; Pélissier, 1989; Roche, 1985; Rodney 1970; Teixeira da Mota, 1954). No país, que havia recentemente se tornado independente, esse tipo de sociedade era bem exemplificado pelos 
balantas, que tiveram um importante papel durante a luta pela independência. Para Cabral, o futuro imaginado para a Guiné-Bissau como Estado-nação deveria ser o de uma sociedade horizontal e igualitária, retomando a continuidade com o passado profundo que fora rompida com a chegada dos europeus e com o desenvolvimento de estruturas verticais, hierárquicas e, consequentemente, com o surgimento de marcadas desigualdades sociais.

Quando cheguei à Guiné-Bissau, o projeto de uma nação socialista e igualitária, livre das contradiçóes típicas das sociedades fortemente estratificadas e desiguais, já não tinha mais os contornos da utopia que até poucos anos antes atraíra um grande número de ativistas europeus que trabalhavam como cooperantes no país, esperançosos de viver o paraíso da sociedade sem classes. Tampouco era vivido pelos guineenses como a promessa de redenção de um passado de exploração e de dor. A nação da vida era distante da nação do projeto, e a diferença entre elas certamente não era favorável à nação vivida cotidianamente.

O segundo projeto para a naçáo, que começava a disputar hegemonia com o "retorno às origens" de Cabral e avançava a olhos vistos entre os empresários, a elite dos servidores estatais ligados ao comércio exterior e às finanças e os atores nacionais trabalhando para as agências de cooperação multilaterais, como o Banco Mundial e o FMI, propunha um desligamento entre o Estado e a nação. A sugestáo implícita era que o primeiro deveria recuar para os bastidores deixando que as forças do mercado impessoal e anônimo arbitrassem os conflitos e dessem um contorno geral e institucional à nação. Não deixava de ter uma dose de má comédia, muito trágica, por sinal, esse macaquear repetitivo ao extremo de proposiçóes que funcionam, a bem dizer no modo da lambança, em lugares em que mercado, forças anônimas e impessoais têm existência reconhecida. A coisa vinha a desandar de fato quando os moços, belos ou pobres moços, falantes do mais impoluto javanês, começavam a ter êxito em convencer os homi grandi (os poderosos tradicionais) da terra de que o mercado substituiria o Estado corrupto, ineficiente e blá-blá-blá.

Logo a seguir ao descomprometimento do Estado com a nação, onde este claramente a precedia, vieram as privatizaçóes das poucas empresas públicas, o multipartidarismo e as eleiçóes livres. Muita gente enricou rápida e demasiadamente através de tramas e conluios que nem os rumores mais fantasiosos conseguiam desvelar. A vida social deu vazáo a uma verdadeira economia do oculto, na trama da qual a imaginaçáo das ruas comentava voluptuosa os atos de canibalismo, as mortes rituais e o tráfico de órgãos e de crianças com vistas à acumulação de poder. ${ }^{16}$ 
Começava por essa época na Guiné o que veio a ser conhecido em toda a África como programas de reajustamento estrutural, que não são de boa memória, vistos com os olhos de hoje. Se de início houve esperança, e a nação por trás do projeto neoliberal pareceu conquistar alguns coraçóes e umas tantas mentes, não tardou muito e as mesmas mazelas voltaram à tona, a autoridade sufocante dos grandes e poderosos manteve-se impávida a bloquear as esperanças tênues da valia e do mérito, e as redes patrimonialistas (sem a legitimidade dos grupos corporados tradicionais, como os grupos de descendência, os conjuntos etários e as associaçóes de culto e iniciação), cada vez mais frouxas, continuaram a sugar e controlar os diminutos recursos disponíveis na sociedade. $\mathrm{E}$, assim, rapidamente retornaram às ruas de Bissau duas nostalgias. A primeira, a saudade da utopia de Cabral e de um misterioso, pois inexistente, PAIGC de raiz. A segunda, perversa como o quê, era a saudade imperial (Trajano Filho, 2008c, 2010a; Vigh, 2006).

Mas, a rigor, não eram esses os projetos de nação que eu procurava. Eu não estava interessado na nação oficial, produzida nos gabinetes institucionais, nem na mimese automatizada de um modelo original, produzido na Europa do século XIX, disfarçada porcamente com aquela vulgaríssima, pois esperada, mão de tinta mal dada - cuja pretensão, em todo lugar, é conferir alguma cor local à cópia. Acho que a nação vista de cima pode ser muito cara aos politólogos e profissionais das relaçóes internacionais, aos especialistas em qualquer coisa e tudo mais que frequentam, vaidosos, os programas de opinião previsíveis da televisão e aos expertos daquele tipo de instituição deseducada que vivem de recusar o bom convite. ${ }^{17}$ Mas os antropólogos não acham muito gozo na perspectiva de cima para baixo. Foi, pois, descontente com o olhar oficial que comecei a procurar pelos projetos não oficiais para a nação, pelas imagens formuladas de baixo para cima, pelas ideias frequentemente contraditórias para o devir coletivo.

Tive a certeza de ter encontrado o que procurava no dia em que ouvi um rumor sobre perigosos cortadores de cabeça (sempre retratados como estrangeiros) que andavam pela terra a decepar e mutilar a gente comum do país. Poucos dias depois de ouvir esse rumor, li no único jornal da Guiné, órgão de comunicação do partido e do Estado, que, "boato ou não, a polícia estava de alerta" contra esses malfeitores que vinham perturbar a ordem da vida nacional (Trajano Filho, 1993a, 1993b). Foi essa manchete do jornal No Pintcha que me pôs a caçar como cão farejador os rumores sobre o que os guineenses pensavam sobre eles mesmos, sobre a naçáo em que viviam um duro e imprevisível cotidiano e sobre os outros (brancos e pretos, tugas, senegaleses, gente da Guiné Conacri bem como a malta africana de proveniência diversa) que, por contraste e semelhança, acabavam por lhes dar a feição que pintavam de si. 
Foi, então, correndo atrás de rumores variados - estórias sobre os poderosos, sobre os governantes, sobre a gente comum, sobre o poder, seu excesso e sua carência - que achei um novo tópico para minha pesquisa. Era a nação das ruas, dos mercados, dos táxis compartilhados, dos bancos improvisados às sombras das mangueiras a funcionar como bantabas onde se reuniam em animados jumbays as gentes dos bairros de Bissau, ${ }^{18}$ que encontrara nos rumores: narrativas altamente dramatizadas, de enredo sempre aberto à discussão e mudança (do enredo, das personagens e das açôes) e de eficácia incontestável para criar mundos imaginados de grande efervescência. Assim, mantive meu interesse na nação, como projetos em competição numa arena política, mas os veículos de sua formulação e constituição deixaram de ser oficiais e institucionais e passaram a ser os escorregadios rumores que circulavam freneticamente pela cidade.

Seus autores? Aquilo que comecei a chamar de sociedade crioula e que se tornou minha obsessáo teórica e analítica desde entáo: a menina de meus olhos antropológicos, o que até há pouco me motivava a seguir a despeito dos percalços, ímpetos de desistir e ir criar galinhas, pescar, churrasquear peixe de carne bem branquinha, plantar uvas e fazer vinho.

\section{Sociedades crioulas, crioulizaçáo e colonialismo}

Entendo por sociedade crioula um tipo de formação social que emerge como entidade terceira de um encontro fundador entre sociedades muito diferentes, oriundas de várias vertentes civilizatórias. Nos casos que estudei, ela surge dos contatos regulares entre a vertente civilizacional ibérica, representada originalmente pelos navegadores-comerciantes portugueses que chegaram à costa da Guiné em meados do século XV e pouco tempo depois se fixaram nas ilhas de Santiago e do Fogo, em Cabo Verde, e as múltiplas vertentes africanas, constituídas pelas sociedades costeiras que então ocupavam o território daquela região.

Porém, mais forte do que o interesse nesse tipo societário, minha atenção analítica se voltou desde entáo para o processo que o constitui. Chamei a isto processo de crioulizaçáo. Esse termo tem sido usado pelos sociolinguistas para se referir a um tipo de mudança linguística que se cristaliza numa língua crioula - a língua nativa de uma comunidade de fala que comumente tem um pidgin ou jargão como ancestral (Couto, 1994; Duarte, 1998; Kihm, 1980; Rougé, 1986; Veiga, 2000, para os casos dos crioulos guineense e cabo-verdiano). Como fenômeno sociolinguístico, a crioulização é consequência de um compromisso alcançado por grupos pertencentes a comunidades de fala diferentes, com estruturas econômicas, formas de organização social, instituiçôes políticas 
e sistemas tecnológicos relativamente desiguais - o que pressupóe uma interdependência entre as partes (Trajano Filho, 1998, 2005b).

Justamente com a inspiração advinda de minhas leituras sobre as línguas pidgins e crioulas, a mudança de rumo na pesquisa se deveu também à reverberação provocada em meu espírito pela leitura do instigante artigo de Hannerz (1987), em que ele propunha a metáfora da crioulizaçâo para lidar com os fluxos intersocietários intensos (no seu caso, os fluxos transnacionais do mundo global) e para libertar a descrição etnográfica e a análise antropológica da suposição de que os sistemas sociais e culturais são necessariamente integrados e que as unidades de análise são discretas e autocontidas. Lembro que li esse artigo em 1989, já no Brasil, depois de minha pesquisa de dez meses na Guiné-Bissau. Foi o impacto desse trabalho, juntamente com a descoberta da existência de muitas informaçóes incompletas, de inúmeras zonas sombrias e de diversos tópicos deixados intocados nos longos e solitários períodos de campo em 1987 e 1988, que me fez retornar à Guiné-Bissau em 1992, para mais quatro meses de pesquisa.

Tendo minha investigação na Guiné ganhado uma nova inflexão, passando a ser enquadrada em termos da sociedade crioula que eu observava e do processo histórico de crioulização que a constituiu, minha abordagem passou a ter contornos claramente históricos. Foi ainda durante meu período de campo no país que descobri que deveria contribuir para a consumação do casamento entre antropologia e história (Hart, 1985; Tonkin, 1990) se queria entender plenamente o processo de crioulização que ali tivera lugar. Primeiramente porque, conforme apontou Sankoff (1980: 154), as línguas crioulas são raras, sendo produtos de circunstâncias históricas muito específicas. Por essa razão, um dos tópicos mais abordados na crioulística tem sido o das condições de emergência dos pidgins e crioulos. Aliado a esse hábito sociolinguístico, meu interesse sobre a dinâmica histórica da crioulização se deveu a uma inspiração oriunda de Said (1985), que menciona uma espécie de "início fundacional”, em que um encontro inaugural, de certo modo, conforma a estrutura de possibilidade dos desdobramentos futuros de uma sociedade.

A esse respeito, ao longo do tempo desenvolvi uma perspectiva diferente da que foi alcançada pelos crioulistas acerca da natureza das relaçóes entre os grupos envolvidos na emergência de uma língua e de uma sociedade crioula. O consenso difuso entre esses especialistas sugere a existência de uma forte assimetria entre os grupos envolvidos na crioulização, o que gera relações de intensa subordinação entre eles (Chaudenson, 2001). Essa perspectiva parece-me advir do fato de a crioulística ter se debruçado majoritariamente sobre os processos de formação de línguas crioulas ocorridos no contexto da primeira fase da expansão europeia em 
África e no Caribe, marcada pelo tráfico atlântico de escravos e pela economia de plantation. Este foi um período na história da expansão europeia em que se consolidaram os processos de dominação colonial no Novo Mundo, uma ideologia de classificação das diferenças segundo barreiras raciais, que legitimava a sociedade escravocrata, e o gradual desmoronamento das lógicas do pertencimento e da dependência que caracterizavam as culturas políticas patrimonialistas da Europa medieval e das sociedades indígenas da costa ocidental da África. ${ }^{19}$

Meu argumento é no sentido de rever essa posição. Em primeiro lugar, ressalto que na costa da Guiné não se desenvolveu, até a segunda metade do século XIX, nada que se assemelhasse a uma economia de plantation (o mesmo vale para Cabo Verde). Se é verdade que as sociedades indígenas estavam envolvidas no tráfico de escravos, elas eram ao mesmo tempo produtoras dessa terrível mercadoria, importantes gerenciadoras de sua circulação e vorazes consumidoras ou frágeis vítimas desse sistema intersocietário. Diferentemente das sociedades do outro lado do Atlântico, o mundo indígena da costa da Guiné tinha uma grande dose de controle sobre as três dimensões da escravatura (produção, circulação e consumo).

Em segundo lugar, a perspectiva aqui revista propóe uma generalizaçáo abrangente demais para explicar um processo histórico de longa duração e extrema complexidade. A literatura recente sobre o continente africano está repleta de exemplos que mostram que o período colonial, stricto sensu, não pode ser analisado como a manifestação histórica de uma estrutura binária que reduz as ricas dinâmicas sociais a pares de oposição distintiva do tipo dominado-dominador, colonizadocolonizador, resistência-acomodação (Cooper, 1994; Ortner, 1995). A categoria "colonizador" sempre foi internamente estratificada, e o poder colonial teve de lidar com áreas de sombra onde sua autoridade nunca foi efetiva. Igualmente, o grupo dos colonizados também sempre foi heterogêneo, havendo em seu seio gente extremamente poderosa e gente radicalmente despossuída dos atributos do poder. Havia no mundo colonial resistentes e acomodados, mas, sobretudo, havia uma miríade de variaçóes entre esses polos (Cooper, 1994; Mbembe, 2001; Stoler \& Cooper, 1997). ${ }^{20}$

Além disto, não se deve esquecer que os impérios coloniais eram diferentes: alguns idealizando o exercício do controle direto e total sobre as populaçóes indígenas, outros assumindo a ideologia de um governo indireto, outros, ainda, pela sua autoimagem de fragilidade, não pretendendo mais do que sobreviver em meio às disputas com impérios mais poderosos. E não se deve minimizar o fato de que, por trás das ideologias e dos projetos coloniais idealizados, estava a política real a lidar com os constrangimentos de toda ordem, a dificultar a concretização dos ideais. 
Se nem o colonialismo stricto sensu é plenamente compatível com a explicação binária do tipo dominação-subordinação, o que dizer de processos mais antigos, anteriores à implantação dos regimes coloniais em África e no Caribe, como a crioulizaçáo na costa da Guiné e nas ilhas de Cabo Verde? A singularidade desses casos está ligada ao fato de que a crioulização linguística e cultural que ali ocorreu antecede o desmoronamento das lógicas do pertencimento e da dependência existentes na cultura política portuguesa, a ideologia classificatória ancorada nas barreiras raciais e o desenvolvimento, em meados do século XIX, de uma economia de plantation voltada para a exportação de produtos agrícolas.

Proponho entáo que a forte assimetria entre os grupos envolvidos no processo de crioulização seja substituída por uma assimetria relativa em termos econômicos, sociais, políticos e tecnológicos. Em vez de produzir relaçôes de intensa e permanente subordinação, o encontro intersocietário que acaba por dar à luz uma sociedade crioula pressupóe uma interdependência e um relativo equilíbrio de forças entre as partes envolvidas. Não quero com isto negar as diferenças objetivas entre as unidades sociais que participam desse evento fundador, diferenças que, em tese, poderiam conduzir a relações de dominação. Porém, na arena onde o encontro tem lugar (o cenário de atuação do processo de crioulização), as diferenças não precisam necessariamente produzir uma subordinação estável ou permanente. Elas podem até estar na raiz de relaçôes de dominação que se concretizaram em determinados estágios do processo. Mas, como a crioulização é produto de um compromisso instável e frágil, o grupo que se mostra dominante num determinado momento pode se ver numa situação de subordinação em outro e estabelecer relaçôes simétricas num terceiro momento de observação. A ideia geral é a de que o relativo equilíbrio de forças entre os grupos se mantenha até que o processo esteja consolidado, com a formação das sociedades crioulas com seus mecanismos e instituiçóes próprios de reprodução social. Uma vez bem avançado o processo de crioulização, novas forças sociais podem adentrar o palco e colocar em movimento as engrenagens da dominação.

Foi isto que aconteceu com o mundo crioulo da Guiné. Em minha tese doutoral (Trajano Filho, 1998) mostrei como a sociedade crioula do país tem sido historicamente polimórfica tanto nos projetos e imagens que constrói para si quanto nos princípios de organização social que orientam o seu funcionamento e a sua reproduçáo. Até meados do século XIX, ela era um conjunto de grandes casas patrimoniais organizadas em torno de grupos corporados de descendência bilateral (as Gãs) que intermediavam o comércio intersocietário de escravos entre os traficantes americanos e europeus e os chefes e régulos africanos. Com a crise da economia baseada no tráfico atlântico e na véspera da implantação, de fato, de 
um regime colonial em África, ela assumiu perante os agentes europeus a forma de uma elite lusitanizada fundada numa mística da exclusividade, cujos elementos de distinção eram valores e práticas consideradas cristãs, o uso da língua portuguesa, uma ideologia endogâmica que escondia práticas matrimoniais essencialmente exogâmicas e formas de convivialidade que acentuavam as escolhas europeizantes. Mais tarde, no início do século XX, depois de consolidada a dominação portuguesa, a sociedade crioula experimentou um doloroso tempo de duplo vínculo. Por um lado, fez uma inflexão, se aproximando do mundo indígena. Por outro, assumiu sua situação de relativa subordinaçáo ao regime colonial, atuando como auxiliares cuja reprodução estava condicionada à manutenção da sua própria subordinação. A tensão inerente a esse duplo vínculo contraditório se resolveu gradualmente com a elaboração de um novo projeto a partir de meados da década de 1950. Desta vez, a palavra-chave era o nacionalismo, e a sociedade crioula passou a se ver como nação.

Há ainda uma segunda razão a ancorar meu esforço em consumar o casamento entre antropologia e história no estudo das sociedades crioulas. Ela tem uma natureza puramente teórica e diz respeito ao potencial da crioulização para lançar uma nova luz sobre os fenômenos (diacrônicos por natureza) dos encontros intersocietários, da mistura e da dinâmica social. Desde a segunda metade da década de 1980, antropólogos, sociólogos, historiadores e outros cientistas sociais têm competido numa arena teórica e política para ver qual é o termo que melhor lida com o fato de que as suas unidades de análise frequentemente não são discretas nem autocontidas, suas fronteiras são flexíveis e muitas vezes incertas, e o sentimento de pertencimento a elas nem sempre é exclusivo, dando luz a formas múltiplas de identidade social. Em disputa estão categorias como mestiçagem (Amselle, 1990), transnacionalismo (Basch, Glick Schiller \& Blanc, 1994; Kearney, 1995), sincretismo (Mary, 1999, 2000) e hibridização (Young, 1995), além da crioulização.

Meus trabalhos sobre a sociedade crioula da Guiné-Bissau não deixam dúvidas de que minha opção teórica tem sido ao lado da metáfora da crioulização. Inspirado nos estudos sobre variação sociolinguística em geral (Labov, 1972; Le Page \& Tabourett-Keller, 1985; Milroy, 1992), nas ideias de contínuo póscrioulo e nas escalas implicacionais que ela acarreta (Bickerton, 1973; DeCamp, 1971; Drummond, 1980; Le Page, 1980; Rickford, 1987, 2002), ${ }^{21}$ na noção de sistemas coexistentes (Tsuzaki, 1971) e nas pesquisas sobre aquisição da linguagem e contato entre as línguas (Thomason \& Kaufman, 1991), tenho procurado compreender, através da metáfora da crioulização, a heterogeneidade e fluidez das sociedades e culturas da mistura que surgiram do encontro entre europeus e africanos na costa ocidental da África. 
Mais do que os conceitos rivais, a crioulização me leva além do reconhecimento das misturas, dos fluxos, das interpenetraçôes e da indefinição das fronteiras sociais e culturais. Ela me permite compreender as minúcias do processo de mudança, torna possível apontar quando e em que regiáo do sistema social uma determinada tendência ou um fluxo particular se manifesta e passa a prevalecer, me permitindo ainda circunscrever as fontes e a natureza da invenção social. Tudo isto sem o peso das teleologias perversas que frequentemente vêm de carona com os conceitos rivais. Num trabalho sobre as práticas de nomeação na Guiné colonial, pude mostrar como a metáfora da crioulização permite dar inteligibilidade às variaçóes que caracterizam as sociedades crioulas (Trajano Filho, 2008b).

$\mathrm{O}$ modo como adoto a ideia de crioulização para enquadrar os mundos que estudei é, de alguma forma, singular, se destacando do conjunto dos estudos de crioulização cultural. Estou menos interessado na dimensão da cultura e menos ainda na da identidade. Não me pareceu ser de interesse perguntar pela existência ou não de uma cultura crioula, separada e diferente das culturas indígenas do chão da Guiné. Muito menos tive como principal foco a questão das formas de identificação com uma tal unidade cultural. Na Guiné-Bissau, ao contrário de Cabo Verde, o termo "crioulo" não é uma categoria de identificação. Localmente, ele é usado apenas por um pequeno número de estudiosos do social (sociólogos, antropólogos e historiadores) para se referir de modo impreciso ao grupo de lusoafricanos que vive nos meios urbanos do país.

Meu interesse esse tempo todo esteve voltado para a sociedade — o hóspede frequentemente desconvidado das análises antropológicas contemporâneas, nas quais predominam de modo absoluto o objeto cultura e o método interpretativo de dar a ela sentido. Sem renunciar a tomar analiticamente os símbolos da cultura, procurei examinar as instituiçôes sociais (os grupos corporados chamados Gâs, as associaçôes voluntárias como as manjuandadis e outras tantas) e os mecanismos que, usados numa combinação particular, criam uma estrutura de reprodução social singular, pela qual garantem, por meio da incorporação de coisas, gente e símbolos do exterior, a continuidade transformada da sociedade. Entre outros, os principais mecanismos de reprodução seriam as variadas práticas de adoção de crianças indígenas, as estratégias matrimoniais exogâmicas disfarçadas de endogamia, a incorporação de práticas indígenas de sociabilidade e o comércio orientado pelo padrão de reciprocidade landlord-stranger. ${ }^{22}$

Um par de anos depois de concluída a minha tese de doutoramento, dei início a uma pesquisa de campo em Cabo Verde com o objetivo de comparar o processo de crioulização ocorrido no arquipélago com o da costa guineense. Pensava inicialmente comparar os rumores sobre a nacionalidade nos dois países 
e duas associaçôes voluntárias voltadas para a organização da sociabilidade: a tabanca cabo-verdiana e a manjuandandi guineense. Fiz um trabalho de campo de cinco meses em 2000 e de três meses em 2001 na ilha de Santiago, com uma pequena incursáo à ilha do Maio. A comparaçáo com os rumores nunca chegou a ser feita, pois o material que coletei nas ilhas não foi suficientemente rico para ser comparado com o da Guiné. Por outro lado, a pesquisa com as tabancas rendeu bastante e já publiquei um conjunto relativamente grande de trabalhos sobre elas (Trajano Filho, 2005c, 2006b, 2009a, 2009b, 2011b, 2011c, 2012b, 2014a). Também pude me debruçar comparativamente sobre as associaçóes crioulas de convivialidade em duas oportunidades (Trajano Filho, 2001, 2012c).

Como em toda pesquisa antropológica, a minha investigação em Cabo Verde teve um bônus relativamente inesperado, que veio, de certo modo, compensar a frustração com a pobreza do material que consegui sobre os rumores. Essa recompensa imprevista veio da pesquisa nos fundos do Arquivo Histórico Nacional. Inicialmente, pretendia reunir dados históricos sobre as tabancas de Santiago, mas o trabalho no arquivo terminou por gerar um conjunto rico de informaçóes sobre o estilo do colonialismo português, que se caracterizou como o regime dos fracos, marcado por uma autoimagem que celebra a humildade, pobreza, pequenez e fragilidade dos sujeitos coloniais e dos agentes que colonizam. Escrevi um longo artigo sobre isto, publicado numa coletânea em Portugal (Trajano Filho, 2004), que mereceu um elogio curto e seco do mais ranzinza dos historiadores do colonialismo português em África (Pélissier, 2006).

Ainda tenho muito material inédito que conforma essa visão de mundo marcada pela honra da pequenez, humildade e pobreza. Estou certo de que ele pode ser usado num estudo comparativo dos estilos de colonização dos impérios coloniais em África. A esse respeito me interessam, sobretudo, as comparaçóes inusitadas, por exemplo, entre os impérios coloniais fracos ou de curta duração (no caso, Portugal, Bélgica e Alemanha), mas não deixa de ter interesse o foco nas fronteiras entre os impérios. $\mathrm{O}$ material coletado em arquivos na Guiné-Bissau, em Cabo Verde e em Portugal é bastante rico. Além disso, o conhecimento e a familiaridade que adquiri ao longo do tempo como pesquisador associado ao grupo de pesquisa Integration and Conflict along the Upper Guinea, do Max Planck Institute for Social Anthropology (MPI), sobre o colonialismo francês no Senegal e na República da Guiné e sobre o regime colonial inglês na Gâmbia e na Serra Leoa, me levam a crer que o estudo das fronteiras coloniais é um tópico fascinante, quando relacionado ao estilo de colonialismo. Acredito firmemente que isto é tâo mais verdadeiro quando se tem um entendimento do colonialismo como um regime de poder que está além da exploração econômica e da dominação política, 
alcançando as esferas da percepção do mundo e da experiência cotidiana. ${ }^{23}$ Às vezes penso que o tempo, esse recurso escasso para todos nós, é o único obstáculo a dificultar o mergulho nessa aventura comparativa. Ah, ilusão!

\section{Meus vínculos carnais com a UnB e os desvínculos com a música}

A bem da verdade, a primeira manifestação de um olhar comparativo se deu antes ainda de eu mergulhar na escrita de meu trabalho doutoral. Terminado meu trabalho de campo em finais de 1988 e de volta ao Brasil, sem eira nem beira e com duas crianças para amar e prover, me meti em várias empreitadas antes de começar a escrever a minha tese. Fiz muitas consultorias junto a pequenos produtores rurais em projetos de assentamentos, escrevi textos para candidatos a cargos políticos e, no final de 1990, fui chamado pelo saudoso Martín IbañezNovión, que então era decano de graduação da UnB, para atuar como antropólogo consultor em um projeto de prevenção à malária a ser desenvolvido em São Tomé e Príncipe. Tratava-se de uma proposta feita por um médico brasileiro, macaco velho entre os profissionais da consultoria em saúde, de elaborar uma série de programas educativos (desenhos animados, vinhetas radiofônicas, cartazes e pequenos filmes televisivos) voltados para a prevenção da malária naquele pequeno país africano então assolado pela sezão. Por ter financiamento da Organização Mundial da Saúde, o projeto deveria ter um componente antropológico para orientar os elaboradores dos programas educativos sobre as concepçóes locais de saúde e doença. O trabalho de quatro meses com os santomenses, iniciado em janeiro de 1991, foi muito instigante; já a consultoria propriamente dita foi pouco mais do que desastrosa. ${ }^{24}$

Apesar da enorme frustração com a cooperação internacional, esse trabalho me ajudou a pagar alguns aluguéis, me fez conhecer um outro mundo crioulo e me deu genica o bastante para voltar aos meus dados guineenses, então abandonados pela procura ao pão de cada dia. Retornado das ilhas, escrevi um artigo sobre o carnaval em São Tomé (Trajano Filho, 1993c) e, energizado pelo contato com um segundo universo crioulo africano, retornei de modo muito tateante aos dados guineenses.

Naquela época, dava aulas de antropologia na Faculdade de Direito do Centro Universitário de Brasília (Ceub) e tinha um contrato precário de professor substituto no Departamento de Música da UnB. Esse retorno à música, longe de representar uma religação com o passado, significou um distanciamento. Por essa época, ainda me engajei no que foi meu último esforço de fazer música profissionalmente. Precisando sempre de dinheiro, aceitei a proposta de um amigo para compor a trilha sonora de um episódio de um filme sobre Brasília: 
um longa-metragem tipo colcha de retalhos, composto por vários curtas feitos por diretores diferentes. Posso dizer que nunca fui tão regiamente pago para fazer música como então. E, num grau inversamente proporcional, nunca me senti tão mal trabalhando com o mundo dos sons: havia perdido o ouvido interno, sentia que minha imaginação musical já não era a mesma e precisava cada vez mais do socorro de um instrumento para expressar uma simples ideia.

Foi a última vez que escrevi música. Infelizmente, muito má música, apesar da beleza fácil de alguns temas e motivos. Mas, como Goffman (1974) nos ensinou sobre os símbolos que circunscrevem os rituais de interação, os sinais de encerramento parecem menos elaborados que os de abertura. No mundo ritual, isto talvez indique que é mais fácil pôr fim à prevalência de um quadro da experiência do que estabelecê-lo (Trajano Filho, 2011b). Mas no mundo da vida ou, pelo menos, no da minha vida, as coisas parecem se passar pela inversa. Meu desvínculo com a música nunca se completou, e ela ainda me assombra, afligindo a minha alma que habita hoje no núcleo duro da antropologia. Eu cortei de vez, embora com o arrependimento fingido dos poetas, os laços com a dimensão da sonoridade. No entanto, tenho sido seduzido pela gente tanta que me procura para orientar trabalhos sobre a construção da identidade entre os músicos profissionais, as relações entre música e nacionalidade (no Brasil e em Cabo Verde), os gêneros artísticos e as classificaçóes sociais, a música e a juventude, a música e os processos de patrimonialização (no Brasil e na Colômbia), a prática da improvisação, e a música e a tradição.

Aos trancos e barrancos, terminei de escrever a trilha para um dos episódios e acabei ainda compondo a música para a abertura e o fechamento do filme, bem como as vinhetas entre os episódios. Também a duras penas seguia lecionando as disciplinas de prosódia e de estética musical na UnB. No tempo vago, organizava meus dados da pesquisa guineense e tentava escrever a minha tese. Foi então que descobri que os dez meses de pesquisa na Guiné eram como os queijos canastra de que gosto tanto: cheios de furinhos. Faltavam-me informações sobre várias dimensôes da vida social. Para remediar essas falhas, só um novo período de campo.

Poupei o máximo que pude durante boa parte de 1991 e, em abril de 1992, decidi voltar para a Guiné. Com uma passagem aérea paga pelo CNPq, o último recurso que obtive dessa agência, a compreensão, a boa vontade e o incentivo da amada, uma promessa vaga de trabalho no meu retorno e pouco mais do que um milhar de dólares, segui para Bissau, onde fiquei até agosto do mesmo ano. Minha volta foi, de certo modo, programada pela quebra da promessa de retomar o trabalho no CEUB e pela possibilidade de um contrato de professor substituto no Departamento de Antropologia da UnB. No mesmo dia em que 
cheguei a Brasília, fui submetido a uma entrevista, parte do processo seletivo, e poucos dias depois estava dando aulas na antropologia. Alguns meses depois, fiz o concurso para professor assistente e, assim, consegui um trabalho permanente que me permitiu sentar sobre o material guineense e, lentamente, terminar o doutorado iniciado em 1984.

O convívio com os colegas de departamento ao longo de tantos anos tem sido uma fonte imensa de aprendizado. De meus parceiros tenho recebido apoio e incentivo, bem como desafios de várias ordens. Um deles merece ser ressaltado neste memorial. Trata-se do convite feito em 2002 pelo colega de muitas e boas aventuras Gustavo Lins Ribeiro, àquela altura presidente da Associação Brasileira de Antropologia, para coordenar um projeto que visava fazer um mapeamento da antropologia brasileira a partir da análise das condiçóes de formação dos antropólogos, da pesquisa desenvolvida nos programas de pós-graduação e do estudo das inserçôes profissionais dos egressos desses programas. Assim teve início um projeto de dois anos que culminou, em 2004, com a publicação da coletânea O campo da antropologia no Brasil (Trajano Filho \& Ribeiro, 2004).

Para um estudioso das sociedades crioulas africanas, com a experiência de pesquisa típica dos etnógrafos — o trabalho de campo individual e solitário esse projeto representava uma novidade e um desafio. Tudo que sabia sobre o nosso campo disciplinar vinha de meus dois anos de calvário como coordenador da pós-graduação de um programa de excelência. De repente me vi coordenando um processo de coleta de dados de dimensóes então inusitadas para mim: elementos sobre a formaçáo dos antropólogos e sobre a pesquisa feita em onze programas de mestrado e sete de doutorado, aplicação de um questionário a um público potencial de 887 mestres e doutores egressos desses programas entre 1992 e 2001 e processamento das informações extraídas desse questionário sob a forma de tabelas e gráficos a ser distribuídos aos autores convidados para escrever os capítulos do livro que congregaria os resultados da pesquisa. E, antes de tudo isto, tive ainda que elaborar um enquadramento geral dos temas a serem investigados sob a forma de termos de referência que foram distribuídos aos autores. Trabalhei em estreito contato com os coordenadores de pós-graduação dos programas, com estudantes de pós-graduação dos onze mestrados e dos sete doutorados, que atuaram como auxiliares de pesquisa, e com um grupo de assistentes em Brasília, encarregados de produzir as tabelas e os gráficos. Contei também com a inestimável cooperação de dois colegas com larga experiência em pesquisa quantitativa, especialmente no que dizia respeito ao cruzamento e processamento dos dados oriundos do questionário. 
Dois anos de intensa atividade de pesquisa e quero crer que conseguimos fazer um mapeamento inédito de um campo disciplinar no mundo acadêmico brasileiro. Sei que, passados dez anos da publicação dos resultados dessa pesquisa, um outro grupo está trabalhando num projeto semelhante, de modo que ao final teremos uma radiografia do campo disciplinar cobrindo um período de vinte anos. Isto representará uma fonte de informaçóes fundamentais para nossa atuação nas instituições de ensino e pesquisa e para a boa compreensão da história da antropologia no país.

Devo destacar que a coordenação desse projeto me deu uma perspectiva reflexiva do meu próprio fazer. Até entáo, eu estava alegremente satisfeito com o desenvolvimento de minha carreira. Ingenuamente me contentava com o pioneirismo naturalizado de minha inserção africana e com a marca exótica que isto imprimia no iconoclasta otimista. Foi a pesquisa do campo da antropologia brasileira que fez vir à tona o verdadeiro sentido do caráter pioneiro de minha pesquisa na costa ocidental da África (que tem algo de um campo de luta e que carece ser reivindicado) e me deu um entendimento novo sobre os obstáculos à consolidação das temáticas africanas como uma área de pesquisa na antropologia brasileira.

\section{Estudar a África, diálogos sul-sul e dilemas da internacionalizaçáo}

Fazer uma antropologia da África no Brasil de hoje é se pôr numa encruzilhada tormentosa. Tem algo a ver com a jabuticaba. Lindo, o pé carregadinho, gostosa, a fruta; mas, como metáfora, é estorvo. Porta uma singularidade que melhor estaria velada. Como uma verruga no rosto, à vista de todos, ela atrapalha, se não é que trai, a expressão.

Conforme apontou com muita propriedade Antônio Carlos de Souza Lima (1995), os índios brasileiros são essenciais para a constituição da comunidade imaginada que é o Brasil. ${ }^{25}$ A essa centralidade ideológica corresponde uma centralidade do saber, a saber, a da etnologia indígena no contexto da antropologia nacional. Os negros brasileiros são, nos debates sobre a nação, tão fundamentais quanto os índios, mas isto não é correlato ao lugar da África na antropologia feita no país. Por razóes que não podem ser examinadas aqui, a antropologia da África, em particular, e os estudos africanos, em geral, parecem não ter encontrado um solo fértil no meio acadêmico brasileiro. ${ }^{26}$ Apesar da relevância da temática africana no pensamento dos nossos cientistas sociais da primeira metade do século XX, antes da institucionalização da pós-graduação no país, a África que interessava (e parece ainda interessar) aos nossos antropólogos, sociólogos e historiadores era a que se aclimatara em solo brasileiro, sob a forma de religióes de matriz africana, 
festas e ritos da cultura popular de suposta origem africana, formas associativas das populaçôes afrodescendentes, elementos da cultura material e modos de atuação do preconceito racial.

Se minha memória não me trai, quando elaborei meu projeto de pesquisa sobre a Guiné-Bissau, em 1986, havia no meio acadêmico brasileiro apenas três antropólogos com experiência de pesquisa em África, todos eles estrangeiros. O primeiro, com sólida formação na antropologia africanista inglesa, havia escrito uma importante monografia sobre possessão de espíritos numa comunidade do Zimbábue (Fry, 1976). Uma vez instalado no Brasil, mudou seus interesses de pesquisa, mas, como foi apontado anteriormente, foi um grande incentivador do meu projeto e de outros que surgiram um pouco mais tarde. Os outros dois eram pesquisadores nascidos em África que, por motivaçóes diferentes, deixaram seus países natais e vieram para o Brasil obter sua formação doutoral (Munanga, 1986; Serrano, 2008). Cá, eles tiveram uma formação generalista, escreveram suas teses sobre temáticas relacionadas a seus países de origem e se vincularam ao Centro de Estudos Africanos da Universidade de São Paulo (USP).

Passados trinta anos da escrita de meu projeto de tese, o grupo de antropólogos interessados em África cresceu substancialmente. Hoje em dia, calculo haver cerca de trinta pesquisadores doutores em antropologia nos programas de pósgraduação fazendo investigação no continente africano, a maioria formada no país. Junte-se a estes um pequeno número de sociólogos, um não tão pequeno grupo de historiadores com interesse de pesquisa em países africanos, uma dezena de estudiosos das literaturas africanas, bem como uma centena de estudantes de mestrado e doutorado em todas estas disciplinas que começam a se envolver com o estudo da África, e notaremos que o quadro atual é muito diferente do que havia quando comecei minha pesquisa na Guiné-Bissau.

A primeira curiosidade, à la jabuticaba, da antropologia da África no Brasil que deixa todos nós atolados no dilema da encruzilhada, tem a ver com o fato de que os estudos africanos feitos aqui têm se orientado pela mesma lógica que balizou os que foram conduzidos nos antigos impérios coloniais. Os pesquisadores das potências coloniais sempre preferiram estudar os povos que habitavam as suas colônias ou os assuntos a elas pertinentes. Essa escolha (se é que o termo se aplica) se deveu à necessidade de consolidar e reproduzir as estruturas de dominação implantadas com a presença europeia. Além dos estudos antropológicos com vistas a um maior conhecimento dos povos indígenas, os regimes coloniais patrocinaram o desenvolvimento de outros mecanismos de controle e governo que incluíam a implantação do registro civil, dos sistemas de taxação, dos censos e das missóes geográficas e geológicas, dos códigos de justiça específicos para os indígenas e dos 
procedimentos de demarcação de fronteiras territoriais. O nosso caso é jabuticabal porque o Brasil nunca foi um império colonial. Por isso, é uma curiosidade exótica a lógica de nossa emergente antropologia da África de privilegiar a pesquisa nos países de língua oficial portuguesa, como se estes tivessem conosco um vínculo de ordem especial ou como se tivesse se concretizado a previsão do fado tropical. ${ }^{27}$

O foco obsessivo na "África portuguesa" acaba por prestar um desserviço à consolidação dos estudos africanos no Brasil, pois obscurece semelhanças e continuidades entre, por exemplo, Guiné-Bissau, Senegal ou Serra Leoa e constrói prolongamentos e parecenças duvidosas entre, por exemplo, Cabo Verde e Moçambique, em virtude de nexos históricos muito gerais. A pretensa familiaridade entre as antigas colônias africanas e o Brasil frequentemente radicaliza o desserviço, projetando o Brasil nos Países Africanos de Língua Oficial Portuguesa (PALOPs) e dificultando a formação adequada de nossos antropólogos na etnologia africana.

Um exemplo hipotético: um antropólogo brasileiro interessado nos problemas da pressão sobre a terra ou das religióes neopentecostais na África do Sul dos dias de hoje tornará seu trabalho mais denso se dialogar com os estudiosos desses temas no Brasil. Isto, porém, tem uma natureza suplementar. Primeiro, antes desse engajamento auxiliar, o antropólogo imaginário deve dialogar com estudiosos do fenômeno em Angola, Namíbia, Moçambique e Zimbábue, pois a comparação entre eles é mais estratégica, e as continuidades e descontinuidades existentes certamente encerram sentidos mais fundamentais. Conforme apontei em outra ocasião (Trajano Filho, 2012d), sem a consolidação de uma antropologia dos temas africanos, essa comparação estratégica dificilmente é realizada. Com isto, o diálogo suplementar, que poderia tornar diferenciada a nossa perspectiva sobre o continente, termina por emprestar a ela apenas uma ingenuidade caprichosa, um reinventar da roda ou, pior ainda, a aplicaçáo travestida do conhecido engano etnográfico: African models in New Guinea.

Fazer etnologia africana no Brasil é se colocar numa encruzilhada dialógica em que temos que conversar com os colegas brasileiros que estudam outras coisas (mais comumente o Brasil), com os estudiosos baseados nos centros tradicionais de desenvolvimento da antropologia, com os cientistas sociais dos países africanos em que desenvolvemos nossos projetos de investigação e, por fim, com os pesquisadores situados em lugares outros. Não fazer isto é, pela ordem, (a) se alienar de nossa prática antropológica cotidiana, pagando todos os preços decorrentes dessa fuga para a torre de marfim, em especial os que dizem respeito às honrarias, ao prestígio e às legitimidades acadêmicas; (b) se contentar com o mote "em terra de cego quem tem um olho é rei" e gradativamente perder 
a voz em todos os lugares; (c) romper com o compromisso moral e político de colaborar para o desenvolvimento da ciência nos países mais pobres e, de alguma forma, contribuir (pela inércia) com a perpetuação de uma divisão intelectual do trabalho que produz assimetrias de poder (ou com a continuidade dessa ilusáo); e (d) um pouco de tudo isto, cujo desdobramento maior é abdicar das fertilizaçóes (de ideias) inovadoras e criativas.

Em outras palavras, fazer o que tenho feito dá um trabalho danado. Sinto-me obrigado a fazer ouvir minha voz, pela ordem, no Brasil; na Inglaterra, na França e nos Estados Unidos; na Guiné-Bissau, em Cabo Verde, no Senegal; em Portugal, na Alemanha, na Colômbia, na Holanda. ${ }^{28} \mathrm{~A}$ isto chamamos de internacionalização e, para mim, um de seus atributos mais marcantes é o diálogo sul-sul e as conversações originais e inovadoras. De fato, na academia, o mundo está cada vez mais multipolar, ao contrário do mundo políticojurídico dos Estados nacionais, onde o poder está cada vez mais concentrado e sufocante. ${ }^{29}$ Nela, os centros explodem, se multiplicando, dando à luz centros regionais em forma de rede; as periferias também crescem e antigos quasecentros por afinidade, consanguinidade ou contágio gerado pela proximidade geográfica com centros plenos e certos voltam a ser o que verdadeiramente eram. De modo ainda tímido na academia de hoje, mas de maneira radical em meus devaneios utopicistas, a emergência de novos centros em rede e a reconfiguração dos quase-centros e das periferias produzem a certeza da inexistência de sistemas inerciais de referência absolutos. Isto se intensificará dramaticamente quando as vozes de observadores antropólogos oriundos de uma miríade de sistemas referenciais (todos eles inerciais) convergirem numa mesma plataforma dialógica em que todos conversam com todos (Trajano Filho, 2012e).

Como se já não bastasse ter que dialogar-publicar em inglês, francês, espanhol e até crioulo, para manter viva a fertilização cruzada com os colegas de várias procedências, internacionalizar, no nosso caso, é ter que lidar com uma segunda jabuticaba. Ela se chama Qualis. Trata-se de uma plataforma de ranqueamento das publicaçôes científicas patrocinada pela principal agência de financiamento da pós-graduação no país e elaborada pelos pares, no interior das áreas do conhecimento. É uma ferramenta estratégica para a avaliação da produçáo científica nas avaliaçóes periódicas da Coordenação de Aperfeiçoamento de Pessoal de Nível Superior (Capes). Acontece que, por razóes variadas que não posso examinar aqui, o Qualis da área de antropologia sofre de um forte viés localista, que desestimula o diálogo a sério com os colegas africanos, tornando o esforço por publicar em suas poucas, mas boas revistas, um quase suicídio. ${ }^{30}$ Não conta nada, ou quase. 
Mas a coisa vai mais longe: até pouco tempo atrás, a prestigiada revista Africa, publicada pelo International African Institute, de leitura obrigatória para a formação geral dos antropólogos, era qualificada com um medíocre B2 pelo Qualis da Antropologia. Vale lembrar que nessa revista saíram peças de luminares da história da disciplina, como Radcliffe-Brown, Malinowski, Evans-Pritchard, Fortes, Forde, Gluckman, Turner (e quase todo o grupo de Manchester), Schapera, o casal Wilson, Herskovits, Mary Douglas, Denise Paulme, Marcel Griaule, Levy-Bruhl e, mais recentemente, Fabian, Hannerz, Kopytoff, Fardon, Amselle, Mbembe e outros tantos. Outra revista prestigiosa, o Cahiers d'Études Africaines, pertencente à afamada École parisiense táo incensada em certos círculos locais, sequer era qualificada em nossa plataforma de ranqueamento. A jabuticaba a que me refiro diz que mais vale publicar na revista dos alunos da pós (de qualquer programa) do que em Politique Africaine, African Studies Review, Journal of Southern African Studies, Journal of African History e outras tantas, publicadas em terras onde a bela e deliciosa fruta náo viceja. ${ }^{31}$

A consolidação das trocas intelectuais em redes multissituadas não se faz sem práticas de inserção institucionais. Ao longo de minha carreira de investigador, tive o privilégio de estar vinculado a um conjunto de instituiçóes que me possibilitou boas condiçóes para fazer pesquisa, veicular seus resultados sob a forma de cursos, publicaçóes, conferências, oficinas e seminários, atuar como orientador e membro de bancas examinadoras e ainda discutir e trocar ideias com os colegas docentes e pesquisadores nelas baseados. Quero destacar aqui o Instituto Nacional de Estudos e Pesquisa (Inep) da Guiné-Bissau, que me abrigou durante minhas três estadias de campo no país, em 1987-1988, 1992 e 2007. Além de publicar algumas vezes na revista Soronda (Trajano Filho, 1993b, 1994, 2002b) e no Boletim de Informação Sócio-Económica (Trajano Filho, 1993d), fui muito beneficiado pelo diálogo intenso e criativo com seus pesquisadores, sempre muito generosos.

Em Portugal, o Instituto de Ciências Sociais da Universidade de Lisboa me acolheu como investigador associado em 2005 e 2006, com uma bolsa pósdoutoral da Capes, e como professor visitante em 2010. Publiquei em sua revista Análise Social, lecionei uma disciplina para os alunos de mestrado e doutorado sobre cultura popular africana, atuei em bancas de doutoramento e participei de conferências e seminários organizados por seus pesquisadores, alguns dos quais se transformaram em números temáticos de revistas e livros. Desde o início dos anos 2000, tenho tido um frutífero diálogo com os docentes e investigadores do Instituto Universitário de Lisboa (ISCTE-IUL). No Centro de Estudos de Antropologia Social, vinculado a esse instituto, publiquei três trabalhos em sua 
prestigiosa revista, Etnográfica (Trajano Filho, 2002a, 2006c, 2008b), e participei de conferências e seminários. Fiz parte de bancas examinadoras de teses de doutoramento e sou membro do Comitê Científico Internacional da revista Cadernos de Estudos Africanos, publicada pelo Centro de Estudos Internacionais do ISCTE-IUL.

$\mathrm{Na}$ Alemanha, sou investigador associado do MPI desde 2007, integrando o grupo de pesquisa Integration and Conflict along the Guinea Coast. Nessa condição, tenho orientado teses de doutoramento de jovens pesquisadores, participado de oficinas em que são discutidos os trabalhos dos investigadores, organizado conferências sobre temáticas caras ao grupo e publicado os resultados de minhas pesquisas (Knörr \& Trajano Filho, 2010; Knörr et al., 2012; Trajano Filho, 2010a, 2016). Em duas ocasióes, como associado, me beneficiei do financiamento do instituto para a pesquisa na Guiné-Bissau em 2007 e nos arquivos portugueses em 2011. O MPI tem também disponibilizado recursos para uma grande parte de meus deslocamentos internacionais com vistas a participar de oficinas, congressos e conferências. Devo ressaltar ainda que foi na condiçáo de associado que pude tomar contato direto com o mundo crioulo da Serra Leoa, bem como visitar Gâmbia e Gana. Essas breves temporadas nesses três países da África ocidental me deram uma perspectiva comparativa da regiāo conhecida como costa da Guiné que eu jamais sonhara ter antes de me associar ao MPI.

Tive, por fim, a boa graça de me vincular à Universidade de Cabo Verde (UNICV), onde estive por quatro meses como professor visitante em 2014, no âmbito do projeto de mobilidade financiado pela Capes. Nesses produtivos e encantadores meses que passei nas ilhas de Santiago e São Vicente, ministrei dois cursos de curta duraçáo para os alunos de graduação, proferi palestras, examinei uma tese de doutoramento e uma dissertação de mestrado e co-orientei uma monografia de graduação. Além disso, estando em Cabo Verde, pude estreitar os laços pessoais e intensificar as trocas intelectuais com docentes e pesquisadores da UNICV, o que certamente tornou mais densa a perspectiva que tenho sobre as temáticas da crioulização, cultura popular, colonialismo e identidade nacional nesse país.

\section{Os bastidores e as atividades administrativas:}

\section{o lado menos glamoroso da trajetória acadêmica?}

$\mathrm{O}$ trajeto celebrado neste memorial fica irremediavelmente incompleto se me atenho somente à aventura intelectual e ao mundo do pensamento, deixando de lado as vicissitudes práticas, o diminuto varejo diário, o ruidoso mercado das acanhadas ambiçóes, disputas e cobiças que motivam, despoletam 
e, paradoxalmente, fundeiam as dimensóes mais nobres da trajetória que até agora procurei retratar. Estou pensando nos aspectos puramente institucionais, frequentemente orientados por uma rotina burocrática e pela lógica do gerenciamento que estáo por trás de toda e qualquer aventura intelectual no mundo universitário e acadêmico. À primeira vista, eles parecem se cristalizar em cargos e funçôes por muitos considerados menos relevantes, típicos da região de bastidores, voltados para o apoio à pesquisa e docência. São as atividades ligadas à administração universitária, tais como chefias de departamento, coordenaçóes de curso e participação nos colegiados, nas câmaras e nos conselhos universitários.

Sempre nadei contra a corrente no que respeita a essa percepçáo de nosso envolvimento com a administração. Nunca me senti cativado pelas chefias e direçôes e me acho voluntarioso, desconsertado e impulsivo demais para o seu bom exercício. Por outro lado, não as vejo como fazeres menores e coadjuvantes. Um genérico sentimento caxias (resquício de quatro anos de ginásio em colégio militar?), uma lealdade formativa com a UnB (que passa por uma dimensão difusa de cidadania) e o compromisso (de honra) de sempre entregar tal como me foi dado me levaram a aceitar os encargos administrativos que me couberam por indicação dos colegas. Nunca vivenciei essas atividades no registro do sacrifício, tampouco entrei em disputa por elas. Sempre com elas me envolvi de forma chã, quase blasé. Assim fui coordenador de graduação entre 1994 e 1996, período em que, eu e meu saudoso colega Martín Ibañez-Novión elaboramos os princípios gerais de uma reforma curricular que criaria o que poderia ter sido o primeiro bacharelado em antropologia no Brasil. ${ }^{32}$ Voltei a coordenar a graduação entre 2002 e 2004. Nesse período, fui membro da Câmara de Ensino de Graduaçáo e, como tal, ganhei uma perspectiva mais abrangente da universidade graças ao diálogo regular com colegas de outros departamentos.

Assumi, em 1998, a coordenação do programa de pós-graduação, depois da renúncia da coordenadora de então e de um imbróglio lamentável, mas cada vez mais trivial em nosso meio, de acusaçôes e de assassinato de reputaçóes. Naquela época, o programa tinha perdido (pela única vez em sua história) a nota máxima na avaliaçáo da Capes. A produção intelectual do grupo caíra e parte substancial do programa se transformara numa espécie de igreja que congregava verdadeiros adoradores de ídolos a ouvirem encantados e embasbacados a palavra da salvação e o linchamento de reputaçóes ilibadas. O ambiente estava pra lá de ruim quando assumi a coordenação da pós, incumbido por um grupo de colegas de reverter o terrível quadro que produziu o que considerávamos uma má nota da Capes: aumentar a produção docente, criar condiçóes para uma produção discente sustentável, dissolver a concentração da orientação e desfazer o clima 
de intolerância quase religiosa que se abatia sobre qualquer um que não fosse conformista e não rezasse segundo o credo do bom mocismo que nunca emancipa.

Passados dois anos, o programa de pós-graduação voltou a ter a nota mais alta nas avaliaçóes da Capes (e nunca mais a perdeu), a produção intelectual mudou de patamar e a concentração da orientaçáo em poucos professores se desfez. Tenho certeza absoluta de que, por trás de tudo isto, esteve a qualidade excepcional do corpo docente e dos estudantes do mestrado e doutorado, as boas condiçóes materiais oferecidas pelo programa e a cultura acadêmica que não tinha vergonha da excelência. Mas reivindico um naco dessa glória. Acho que uma pequena parcela da inflexão ocorrida, incluindo a diminuição do poder do culto aos ídolos, se deveu às açóes desse "iconoclasta otimista" (a essas alturas da vida, bastante desprovido da genica da ambição, em sua versão juvenil), em especial à certeza que sempre tive de que fazer bonito, ser bom moço e agradar a todos é o caminho mais certo e direto para o desastre.

Nesses dois anos em que coordenei a pós-graduação, também fui membro da Câmara de Pesquisa e Pós-Graduaçáo da UnB, onde aprendi muito do que hoje sei sobre os desafios que enfrentamos para construir uma comunidade científica nacional de qualidade, pronta para cumprir a parte que lhe cabe na construção de uma nação menos injusta e desigual. Logo que deixei a coordenação, e quero crer por causa de um bom trabalho ali feito, fui convidado a participar do comitê de avaliação da Capes para a área de Antropologia/Arqueologia. As atividades desempenhadas como membro desse comitê, em especial as visitas feitas aos vários programas de pós-graduação, deram-me um panorama da antropologia brasileira que dificilmente eu poderia ter se dele eu não participasse. Tenho certeza de que a experiência adquirida nessa ocasião contribuiu muito para o bom êxito do projeto que coordenei para a Associaçáo Brasileira de Antropologia sobre o campo da antropologia brasileira (Trajano Filho \& Ribeiro, 2004).

Anos mais tarde, entre 2007 e 2008, fui novamente indicado pelos colegas para assumir a coordenação da pós-graduação. Dessa vez, não cumpri os dois anos de mandato. Meu gênio voluntarioso, meu estopim cada vez mais curto e, devo dizer, a falta de estamina de nosso colegiado produziram uma convergência lastimável pela qual o programa perdeu uma oportunidade única de ampliar a interface de diálogo interdisciplinar sem custos institucionais maiores. Frustrado com um surto de covardia coletiva, não tive dúvida: entreguei a coordenação e fui cuidar da vida.

Pelo visto agi bem, pois, três anos depois, fui compelido pelos colegas a assumir a chefia do Departamento de Antropologia, e o fiz por um período de quatro anos, entre agosto de 2011 e janeiro de 2015, o dobro do tempo usual. Neste meu 
último mandato na chefia, exercido em estreita colaboração com a coordenação de pós-graduaçáo, então encabeçada pela colega Carla Costa Teixeira, consolidamos a nossa posição no grupo de excelência da antropologia brasileira.

Quero ainda destacar três tipos de atividades de natureza institucional e de algum modo ligadas à administraçáo que entendo representar um naco de minha contribuição para a conformação do campo disciplinar no país tal como ele se dispóe atualmente. O primeiro tem a ver com minha participação em bancas de concurso para docentes. Trata-se de tomar parte de processos de escolhas cruciais, que, para o bem ou para o mal, definem de modo duradouro as características dos programas de pós-graduaçáo. Participar das bancas de concurso para o quadro de docentes permanentes dos Departamentos de Antropologia da Universidade Federal de Pernambuco (UFPE), Universidade Federal do Rio de Janeiro (UFRJ/ Museu Nacional), Universidade Federal da Bahia (UFBA), Universidade Federal Fluminense (UFF) e USP — todos com programas de pós-graduação consolidados - alargou significativamente minha compreensão do campo disciplinar em nosso país e foi motivo de orgulho pelas escolhas, que, até o momento, parecem ter sido efetivamente as boas escolhas.

O segundo tipo de atividade diz respeito à coordenação geral de um projeto de quatro anos que envolveu, além do programa de pós-graduação em antropologia da UnB, o da UFPE e o Posafro, da UFBA. Trata-se do projeto PROCAD "Relaçôes de alteridade e a produção de diferenças: uma perspectiva Sul-Sul". Com um substancial financiamento da Capes, esse projeto se desenrolou entre 2009 e 2013, representando, no meu entender, um importante passo na consolidaçáo do continente africano como uma área de pesquisa antropológica no Brasil. Trabalhando em estreita cooperação com os colegas Antônio Motta, da UFPE, e Livio Sansone, da UFBA, esse projeto de pesquisa envolveu estágios pós-doutorais, missóes de estudos, cursos de curta duração e seminários temáticos que resultaram na publicação de cinco coletâneas dedicadas à temática africana (Braz Dias \& Lobo, 2012; Motta, Lobo \& Trajano Filho, 2014; Sansone, 2012; Trajano Filho, 2010c, 2012f).

$\mathrm{O}$ terceiro se refere a uma atividade frequentemente relegada a um segundo plano por ser trabalhosa demais. Para piorar, quando é bem feita, acaba por se retroalimentar, produzindo mais demanda e mais trabalho. Além disto, não parece trazer as recompensas que a publicação e a orientação nos dão, apesar de ser táo custosa quanto. Refiro-me ao nosso envolvimento com as atividades de natureza editorial, em especial a três tipos básicos. O primeiro diz respeito ao nosso engajamento como pareceristas de revistas e jornais científicos, que é uma importante instância para a atribuição de prestígio, honra e legitimidade 
acadêmica. Também sem enquadrar isto na moldura do sacrifício, registro que, ao longo desses muitos anos, tenho feito pareceres para as seguintes revistas: Critical African Studies (Reino Unido), Africa (Reino Unido), Etnográfica (Portugal), Sociologia e Antropologia (Brasil), Horizontes Antropológicos (Brasil), Antropolitica (Brasil), Estudos Afro-Asiáticos (Brasil), Cadernos de Estudos Africanos (Portugal), Mana (Brasil), Afro-Ásia (Brasil), American Anthropologist (Estados Unidos), Cadernos de Campo (Brasil), Revista Brasileira de Ciências Sociais (Brasil), Religião e Sociedade (Brasil), Current Anthropology (Estados Unidos), Revista de Antropologia (Brasil), Análise Social (Portugal), Vibrant (Brasil), Anuário Antropológico (Brasil) e Travessias (Portugal). No mesmo registro, fui ou ainda sou membro do Conselho da Editora da Universidade de Brasília e do corpo editorial ou da comissão científica internacional de Mande Studies (Estados Unidos), Afro-Ásia (Brasil), Social Space (Polônia), Cadernos de Estudos Africanos (Portugal), American Anthropologist (Estados Unidos), Anuário Antropológico (Brasil) e Mujimbo (Brasil).

\section{Atividades de formaçáo}

A formação de antropólogos, por meio do trabalho de orientação da pesquisa e da escrita de monografias de final de curso, dissertaçóes de mestrado e teses de doutorado, talvez seja uma das atividades mais nobres da carreira docente nas instituiçóes que mesclam pesquisa e ensino, como é o caso da UnB. Participar como ator estratégico da metamorfose de um jovem estudante num colega é uma dádiva, eu diria a mais impagável delas todas, da trajetória acadêmica que aqui busco celebrar. Observar o crescimento pessoal e intelectual de nossos alunos e perceber que somos parcialmente responsáveis por esses caminhos acaba por provocar em todo professor um precioso sentimento de autorrealização. Notar que, com o passar do tempo, aprendemos mais do que ensinamos e que muitos de nossos antigos estudantes estão mais bem formados do que nós, têm uma produção mais densa e têm ou terão uma carreira mais congruente e exitosa do que a nossa é uma coisa pra lá de recompensadora.

Não tive um grande número de estudantes em minha já longa carreira, quando a comparo com a atividade de orientação de outros colegas. Imagino que uma imerecida fama de excesso de rigor, uma suposta inflexibilidade e um jeitão autoritário (falso que só!) estáo na raiz dessa relativa impopularidade. Ao longo de 23 anos de carreira docente na $\mathrm{UnB}$, foram concluídas nove monografias de graduação, oito dissertaçóes de mestrado, sete teses de doutorado e um estágio pós-doutoral sob minha orientação. Na Martin-Luther Universität, em associação com o MPI, co-orientei uma tese de doutorado. Atualmente oriento dois estudantes 
de mestrado e um de doutorado na UnB e co-oriento uma pesquisa doutoral no meu grupo de pesquisa do Max Planck.

Posso dizer sem medo de errar que as temáticas e as áreas empíricas desses trabalhos foram muito variadas. Meus alunos fizeram pesquisa em casa (a totalidade das monografias de graduação), lidando com associaçóes voluntárias locais, eventos e cenas da cultura popular e grupos profissionais e religiosos. $\mathrm{Na}$ pós-graduação, eles se envolveram com investigações em vários cantos do país, lidando com grupos indígenas no Sul, processos institucionais em escala nacional, práticas de cultura popular no Nordeste e no Sudeste, processos de estruturação de grupos profissionais e o fenômeno da juventude e suas gangues e galeras. Porém, o que mais tem marcado minha atividade de orientação é meu envolvimento com a pesquisa fora de casa, em contexto internacional. Assim, orientei trabalhos sobre movimentos sociais indígenas no México e sobre processos de gestão do patrimônio cultural na Colômbia.

O continente africano, área em que minha própria investigação representa a principal contribuição que fiz para o campo da antropologia no país, tem sido o local estratégico em que a atividade de orientador converge com a reproduçáo de minha trajetória intelectual e de meus interesses de pesquisa. Voltados para a África, orientei trabalhos sobre organização familiar em contextos migratórios (Braz Dias, 2000; Lobo, 2007), percepção da paisagem (Lobo, 2001) e relação entre gêneros musicais e identidade nacional em Cabo Verde (Braz Dias, 2004). Fora do ecúmeno lusitano, supervisionei a pesquisa sobre as relaçóes de poder e conflito entre os hereros da Namíbia (Castro, 2009, 2013) e sobre identidade étnica e nacional na Serra Leoa (Ménard, 2015).

O privilégio de orientar táo seleto grupo de jovens antropólogos se deixa ver claramente em dois traços que caracterizam as suas trajetórias individuais. Por um lado, os prêmios que eles têm recebido e as crescentes publicaçóes de suas dissertaçóes e teses e, por outro, o envolvimento de alguns deles na carreira docente, em prestigiados programas de pós-graduação.

Sobre o primeiro traço, registro que João Miguel Sautchuk recebeu uma menção honrosa do Prêmio Silvio Romero em 2006 por sua dissertação de mestrado sobre a gravadora Marcus Pereira (2005). O mesmo autor foi premiado com outra mençáo honrosa do Silvio Romero em 2009 pela sua tese de doutorado sobre cantadores e repentes no Nordeste brasileiro. A qualidade dessa tese é inequivocamente atestada pelas menções honrosas que também recebeu no Concurso Brasileiro Anpocs de Teses e Dissertaçóes Universitárias em Ciências Sociais em 2010 e no Prêmio Capes de Tese em 2011 e pelo Prêmio Mais Cultura de Literatura de Cordel em 2013, dado pelo Ministério da Cultura na categoria Pesquisa. Também foram recipientes 
de prêmios acadêmicos a dissertação de mestrado de Rivia Ryker Bandeira de Alencar, intitulada Será que dá samba? Mudança, Gilberto Gile patrimônio imaterial no Ministério da Cultura, com a mençáo honrosa do prêmio Silvio Romero de 2005, e a tese de doutorado de Josué Tomasini Castro sobre as relaçóes de poder e conflito entre os hereros da Namíbia, com a menção honrosa no Concurso de Teses e Dissertaçôes da Anpocs em 2014.

Além dos inúmeros artigos e capítulos de livros publicados no Brasil e no exterior, quero destacar a publicação, pelos meus antigos orientandos, de suas teses doutorais sob a forma de livro, com maiores ou menores mudanças. Patrícia Trindade Maranhão Costa (2012) publicou seu trabalho sobre as congadas de Serra do Salitre. De João Miguel Sautchuk (2012), foi publicada, sob a forma de livro, a sua investigaçáo sobre o repente nordestino. Em Cabo Verde, pela editora da UNICV, Andrea de Souza Lobo (2012) fez sair o seu trabalho sobre as famílias e os fluxos na ilha da Boa Vista, numa clara demonstração do esforço coletivo que fazemos aqui de estreitar o diálogo sul-sul, privilegiando como leitores as pessoas dos locais onde realizamos nossas investigaçóes.

Assistir de perto e ter a consciência de que, de alguma forma, tenho contribuído para o processo de transformação do pesquisador em professor produz na alma um arrebatamento que compensa os dissabores em pequena escala da vida cotidiana. Faz sentir que valeu a pena e que foi (bem)feito o esperado. Com essa inebriante sensação, dois outros sentimentos emergem: a alegria e o orgulho. O primeiro tem a ver com a certeza de ter tido êxito na empreitada de reproduzir a si e as ideias. Num contexto em que se celebra uma trajetória acadêmica e intelectual, o eu e as suas ideias se mesclam e se dissolvem um no outro. Tal mistura e tal diluição, associadas ao sentir-se arrebatado, remetem a uma excitaçâo incontrolável do espírito, cujas raízes se encontram em Eros. Por isto, assistir à transformação de meus antigos estudantes-pesquisadores em docentes tem algo de orgástico, é repleto de alegria, gozo e amor. Mas, quando a transformação sobre a qual reflito deixa de ser genérica e meus antigos alunos passam a ser mais do que docentes e se tornam meus colegas de departamento, ao júbilo arrebatado se agrega o orgulho — o bom orgulho, o que não vem com empáfia nem soberba. É assim que me sinto desde que passei a ter como colegas os meus antigos orientados Juliana Braz Dias, Andrea de Souza Lobo e João Miguel Sautchuk.

\section{Coisas ainda devidas, sínteses a serem feitas e horizontes de futuro}

Se quero, como sugeri no início, evitar o tom de lamento (e a dor e o pesar a ele associados), me afastar, por mais sublime que seja, da forma réquiem, e manter 
distância do deus Tânatos, devo terminar este memorial com uma afirmação de futuro. Mas, como espero ainda muitas coisas fazer, talvez devesse melhor falar em projeção de futuros - irreverentes, certamente, incongruentes, incompletos e descumpridos futuros.

Os projetos mais óbvios são quase sempre postos de lado em nome da urgência um tanto fantasmagórica que penetra forçosamente o cotidiano acadêmico e faz com que os preguiçosos a critiquem como produtivismo. Encontrar um valor e uma prática que aplaquem a ilusão da urgência e acabem com o preguicismo lombriguento, que estejam a meio caminho entre publicar (qualquer coisa) e morrer e a "denúncia vazia" dos senhores proprietários do mercado acadêmico, ${ }^{33}$ ainda parece uma quimera remota, mas nem por isto inalcançável.

O projeto primeiro (por ser o mais antigo) é completar a atualização, por meio de comentários sob a forma de boxes, e a revisão de meu trabalho sobre os músicos profissionais. Decantada a ingenuidade estudantil do texto original (uma dissertação de mestrado), sobra um caldo denso e complexo, com taninos arredondados a prometer uma vida ainda longa ao texto. A parte central desse trabalho analisa os rituais básicos do mundo dos músicos, verdadeiros atos de música que acabam por constituir de fato o grupo profissional: os ensaios de orquestra e o concerto musical. Uma primeira e mais severa revisão do texto já foi feita, e cerca de metade dos boxes foi escrita. Não falta muito, além da dedicação e de um pouco de tempo.

Outra dívida que tenho comigo é a escrita de um livro sobre a Liga Guineense. Trata-se de uma associação voluntária do mundo crioulo, criada em 1910, que congregava os principais comerciantes nativos da Guiné. Escrevi um longo capítulo sobre ela e seus membros no contexto do que chamei de movimento protonacionalista (Trajano Filho, 1998). Os dados primários usados nesse trabalho vêm de depoimentos de descendentes dos antigos associados, de material de arquivo coletado em Bissau, de textos dos principais atores sociais envolvidos no conflito que levou à sua dissolução e à prisão da maioria de seus diretores e da parca historiografia existente (Mendy, 1994; Migueis, 1937; Pélissier, 1980; Pontes, 1912; Santos, 1968; Teixeira, 1917; Teixeira Pinto, 1936; Vasconcelos, 1916). ${ }^{34}$ Para concluir o projetado livro, precisava ainda investigar os arquivos portugueses em busca de material primário que adensasse a análise e tratar de modo comparativo as açóes da associação crioula, tendo como pano de fundo o contexto da implantação de fato de um regime colonial na Guiné e as reaçóes ensaiadas pela sociedade crioula local para lidar com a perda provisória das rédeas de seu devir. 
Para dar conta disso, elaborei o projeto "A Liga Guineense: disputas identitárias coloniais e a continuidade com a cultura política pós-colonial na Guiné-Bissau". Com financiamento do MPI, passei quatro meses em 2011 levantando material sobre o tema no Arquivo Histórico Ultramarino e no Arquivo Nacional da Torre do Tombo em Lisboa. Assim, a escrita e publicação desse livro é também uma dívida que tenho com esse instituto alemão, que tem sido, desde 2007, muito generoso com meus pleitos de investigação. $\mathrm{O}$ estado atual desse projeto não é lá muito animador, por isto uma ansiedade me assola sempre que penso nele. Além do capítulo já escrito, tenho muitas centenas de páginas de documentação colhidas nos arquivos portugueses e nos jornais de Lisboa e das colônias sobre o tema, bem como algumas entrevistas com familiares de diretores da Liga que fiz em 2007, durante quatro meses de pesquisa de campo em Bissau, também com recursos do MPI. Como se depreende dessas notas, ainda falta muito para o projeto chegar a ser concluído, mas, como sou tinhoso, um dia eu dou cabo disto.

Um terceiro projeto diz respeito à minha pesquisa sobre a tabanca caboverdiana feita em campo entre 2000 e 2001 na cidade da Praia e no concelho de Santa Catarina, na ilha de Santiago. Até agora publiquei oito artigos e quatro capítulos de livro sobre o assunto (Trajano Filho, 2001, 2005c, 2006b, 2009a, 2009b, 2011b, 2011c, 2012b, 2012c, 2014a, 2015, 2016). Por se tratar de uma temática que reputo de interesse etnográfico e teórico (envolvendo a crítica aos conceitos de resistência e mimese, pelo desafio de fazer uma análise de quadros e pela reflexão sobre a modernidade), parece-me relevante juntar todo esse material num único livro voltado para as tabancas de Cabo Verde, já que o material publicado até agora está disperso em revistas e livros saídos em Cabo Verde, França, Inglaterra, Colômbia e Brasil, nem todos de fácil acesso. O trabalho maior na consecução dessa tarefa será reduzir ao máximo a repetição e encontrar um fio condutor narrativo e analítico congruente. Não é uma empreitada fácil e rápida, mas não demanda uma enorme energia vital. O problema para realizá-lo é o mesmo dos outros prospectos: o tempo, cada vez mais um escasso recurso.

Um penúltimo projeto veio à luz originalmente numa conferência que fiz em 2006 no Departamento de Antropologia da Universidade de Coimbra sobre a inflação semântica que acaba por retirar a produtividade analítica do conceito de mimese. Este texto foi depois apresentado, com modificaçóes substanciais a cada vez, no Instituto de Filosofia e Ciências Sociais da UFRJ, no Departamento de Antropologia da Universidade Federal do Paraná e no Instituto de Ciências Sociais da Universidade de Lisboa. A partir daí, associei a ideia de inflação semântica à de obesidade conceitual no contexto de produção da teoria antropológica marcado 
pela tendência à superinterpretação. Essas ideias foram apresentadas numa série de três conferências proferidas na Escola Nacional de Antropologia e História (cidade do México) em 2013 sobre a obesidade conceitual, a mimese e a ideia de resistência. Em outra ocasiáo, numa conferência intitulada "O problema da superinterpretaçáo na antropologia contemporânea”, proferida em 2014 nos Seminários de Estudos Pós-Graduados no Instituto de Ciências Sociais da Universidade de Lisboa (reapresentada com modificaçóes numa oficina de meu grupo de pesquisa no MPI em 2015 na cidade de Dusseldorf), pude alinhar de modo genérico o conteúdo de todas essas apresentaçóes. Falta-me no futuro organizar essa série de trabalhos sobre o uso de conceitos na produção da teoria antropológica e nas análises etnográficas num único volume. Este é um trabalho de maior envergadura e espera por um terceiro conceito assolado pelo câncer da inflação semântica, que exemplifique um caso adicional de obesidade (além da mimese e da resistência), e por uma solução dessa aporia teórica que vá além da crítica que demole e tenha uma natureza positiva. Como um terceiro conceito a exemplificar a manifestação da obesidade conceitual, estou inclinado, mas em dúvida, entre a onipresente "identidade" e o confuso e cada vez mais inflacionado "gênero". Quanto à solução positiva da aporia, tudo que posso fazer agora é retomar o mote romântico do exílio e dizer "não permita deus que eu morra sem que..." (apesar de ser um ateu empedernido e inveterado).

Menos distante e mais chão, por ser uma necessidade associada a um mínimo de congruência que uma trajetória intelectual parece demandar, ${ }^{35}$ é meu projeto de refletir sobre os dois interesses temáticos que têm caracterizado meu percurso intelectual: a crioulizaçáo e a cultura popular. Trata-se de uma das "sínteses ainda a serem feitas" que é parte do nome desta seção. De maneira ainda muito tentativa, começo a perceber que a cultura popular, entendida como uma dimensão da vida social que não liga a mínima para o fato de as coisas estarem permanentemente fora do lugar, onde as mensagens são portadoras de autonegação tão logo são esboçadas ou emitidas, encontra solo fértil para florescer em situaçóes sociais marcadas pelos fluxos, encontros e compromissos intersocietários que defino como situaçôes de crioulizaçấo. Juntando cultura popular com crioulização, imagino estar integrando de modo criativo duas linhas de investigação que só poderiam se conectar graças a um nexo biográfico particular: a linhagem dos estudos sobre o popular na cultura nacional, que gerou acalorados debates no Brasil dos anos 1960 e 1970 e que parece ter se exaurido desde meados dos anos 1980, e os estudos sobre cultura popular africana tal como protagonizado por Fabian (1978, 1998), Hannerz (1987, 1996) e Barber (1997). 


\section{Concluindo...}

Quero terminar com a menção a um projeto que não é substantivo ou temático, mas que tem a ver com estilo e experimentação formal. Trata-se de um dos devaneios que tem me motivado a continuar batendo cabeça, insistindo em insistir na vida "fora de moda" para melhor sobreviver à "queda livre", tentando fazer uma síntese derradeira em busca de um dedinho que seja de congruência — entre meu passado esvanecido de músico e minha trajetória antropológica voltada para os mundos em crioulização. Ainda sonho em fazer um experimento de natureza formal, fortemente centrado na manipulação da linguagem, que dê expressão direta à antropologia da babel crioulizada que vencerá a barreira linguística da ininteligibilidade entre as comunidades de fala e escrita. Esta antropologia seria essencialmente crioula, sua linguagem seria múltipla e cambiante, cheia de empréstimos e carregada daquilo que os linguistas chamam de code switching. Resta saber quem iria publicar e quem iria ler.

Esse meu devaneio utópico seria uma antropologia universal e cosmopolita, produto de diálogos transversais sul-sul, norte-norte, entre todos os sules e todos os nortes, entre os centros que se multiplicam e as periferias também obesas e inflacionadas em número. A fonte que inspira esse saber estaria num outro ícone, de uma outra língua (sem nunca alcançar a estatura d'Ele). Penso aqui em Umberto Eco, o ficcionista semiótico que deu luz a Salvatore, personagem que reverbera de modo um tanto abstruso a encruzilhada em que me encontro: eu, o iconoclasta otimista, de súbito me vejo, não sem o rubor do embaraço, identificado com esse herege meio débil mental que parece falar uma língua particular que é a mistura de todas as línguas (um crioulo?). No fundo, no fundo, a trajetória sobre a qual estou prestes a concluir não é outra que a da transformação do iconoclasta musical que ambiciona se tornar o herege antropológico, nadando contra a corrente, às vésperas de deixar o jogo.

Essa antropologia do devaneio é, na realidade, uma utopia, pois descentra ou dissolve, no registro da redução filosófica, do pôr entre parênteses, todo poder e toda dominação que sufocam a alma e o pensamento. Mas, paradoxalmente, é uma antropologia que quer pôr novamente o acento no universal (sem desconsiderar a diferença e sem cometer velhos pecados), que quer voltar a ser ciência (sem esquecer a história e a poesia) e que sonha ser verdadeiramente uma prática e um olhar humano. Por isto é avessa ao bom-mocismo tão em voga nos nossos círculos e desdenhosamente acha graça dos projetos bem-intencionados mas quase nunca realizados das autoetnografias, das etnografias invertidas duais e dos discursos da simetria. Meu sonho é mais ambicioso, mais radicalmente universal e, por isto, talvez, mais factível: antropólogos trobriandeses interessados no mundo nilótico, 
de onde saem pesquisadores que querem compreender as sociedades andinas, que formam etnólogos que investigam as heterodoxias religiosas do Oriente Médio, cujos especialistas do social se voltam para o pensamento mágico-religioso do norte europeu, onde são formados investigadores que estudam as culturas políticas da China e da Índia, que produzem estudiosos ávidos por compreender a cultura popular antropofágica em voga no Brasil, de onde saiu esse atribulado e caótico etnógrafo do mundo crioulo da costa ocidental da África. Tudo isto num crioulo herege, assado no forno de todas essas línguas.

Deixando a utopia que perscruta o segredo do futuro das coisas e mergulhando na reflexáo que focaliza o caminho que percorri, retomo o espírito mimético e volto às práticas imitativas que servem de fundamento para o aprendizado artístico. Quero que esta conclusão seja toda de afirmativas. Acho que tive uns cinco minutos (bem localizados) de fama, náo fui ministro nem califa, mas professorei a vida inteira, conheci o casamento. Verdade é que, ao lado dessas conquistas, coube-me a labuta de comprar o pão com o suor do meu rosto. Mais; tive a boa vida, sem padecer o sofrimento de tantos que conheci, nem a semidemência do Quincas Borba. Somadas umas cousas e outras, qualquer pessoa imaginará que não houve míngua nem sobra, e conseguintemente que estou quite com a vida. E imaginará bem; porque ao chegar a este outro lado da narrativa, acho-me com um grande saldo, que é a derradeira afirmativa deste parágrafo de afirmativas: Tenho filhos (e neto), transmito a eles o legado de minha ventura e consolo-me com a saudade de mim mesmo. 


\section{Notas}

1. Não resisto à tentação de apontar a diferença entre o epígono e o herói-mestre. Enquanto o último preza pela clareza, ausência de excesso e parcimônia no texto (vassouras e espanadores), o primeiro é guloso e verborrágico em sua imitação. Não prezo o gesto obeso e o exagero, mas náo consigo evitá-lo.

2. Os trabalhos referidos sáo um duo para violino e violoncelo (Trajano Filho, 1977) e uma peça experimental para qualquer formaçáo instrumental (Trajano Filho, 1980), esta última meu trabalho mais executado graças ao incentivo do colega Nei Rosauro, que veio a se tornar uma referência mundial na percussão. Nei preparou e executou com muita sensibilidade uma versão para múltiplos instrumentos. Sua leitura dessa peça, chamada "Brasília", foi executada em várias salas de concerto pelo mundo, mas eu só pude ouvi-la uma única vez. Com a menção ao Nei, quero expressar a saudade imensa e doída que tenho do tempo habitado por uma gente outra.

3. Também em tom confessional digo que reli o tal texto durante a redação deste memorial. O sentimento produzido pela leitura da maturidade foi ambivalente: um misto de frustração causada pela mistificaçáo erigida pelo autor em torno da relação entre mito e música (um curioso sentimento de ter sido enganado) e uma satisfação um tanto boba em detectar essa quase-impostura e não cair tão facilmente na esparrela.

4. Em Trajano Filho (2008a), eu relato como as análises de Goffman inspiraram esse meu primeiro trabalho de pesquisa antropológica. Em Trajano Filho (2011b), procuro aplicar a análise dos enquadramentos oriunda de sua microssociologia aos cortejos feitos pelos membros das tabancas cabo-verdianas.

5. Na realidade, tais experimentos eram uma das múltiplas manifestaçôes das circunstâncias cambiantes em que se produzia a antropologia cultural nos Estados Unidos. Tais conjunturas em transformação produziram um grande grupo de descontentes na disciplina (Scholte, 1971), que se propunha de algum modo a experimentar.

6. Para ser preciso, tinha me chegado em mãos um artigo de Marcus e Cushman (1982) publicado no Annual Review of Anthropology e uma monografia de Stephen Feld (1982) sobre mito e música na Nova Guiné. Estes eram os únicos indícios que eu tinha de que algo estava mudando na escrita antropológica fora de casa.

7. Lembro-me de que a primeira versão desse trabalho era muitíssimo mais radical do que a que foi dada a público. Devo a saudável domesticação da invenção estouvada ao bom senso de Mariza Peirano, minha orientadora, que me convenceu delicadamente a, por assim dizer, entrar nos trilhos.

8. Foi com essa locução que um outro mestre, o meu professor de composição, Claudio Santoro, uma vez me definiu. Acho que foi com apreço e consideração.

9. Filho de pais russos refugiados em Xangai, onde passou a infância e adolescência, Igor Kopytoff teve uma trajetória mais do que peculiar. Saiu da China aos 18 anos, viveu dois anos no Chile e, a seguir, um período nas colônias inglesas da África oriental. No início da década de 1950, foi para os Estados Unidos fazer seus estudos universitários 
e concluiu, em 1960, o doutorado na Northwestern University, sob a orientação do decano dos estudos africanos, Melville Herskovits. Sua história de vida e os traços de sua personalidade fizeram dele também um iconoclasta, e talvez tenha sido essa sua marca o que me levou a escolhê-lo como orientador de minha tese.

10. A biblioteca setorial do departamento de antropologia, sediada no museu da universidade, era excelente e quase tudo que não havia nela podia ser encontrado na fabulosa biblioteca central. A parcimônia de obras sobre a Guiné-Bissau não se devia, portanto, a uma carência do acervo, mas propriamente à relativa pobreza de investigaçóes feitas no país. Tive acesso à coleção completa do Boletim Cultural da Guiné Portuguesa (publicado entre 1946 e 1973), a cerca de uma dezena de monografias publicadas na época colonial pelo Centro de Estudos da Guiné Portuguesa sobre a história do país e etnografia de alguns de seus grupos étnicos, a alguns textos de historiadores e cientistas sociais saídos depois da independência, em 1974, e à obra de Amílcar Cabral, onde eu podia encontrar o projeto nacionalista para a nação.

11. Uma vez em campo, logo descobri que a familiaridade natural dada pelo hipotético compartilhamento da língua era um engano crasso. No aeroporto de Bissau, aprendi de súbito que, para as pessoas dali, o português era uma língua tão ou mais estrangeira do que o francês. Refleti sobre esse engano em Trajano Filho, Thomaz, Dias e Silva (2008).

12. Vim conhecer a expressão "pés vermelhos" através do texto de Chabal (1983). Ela era usada no período pós-independência para se referir às centenas de intelectuais, técnicos e consultores das agências internacionais de cooperação e das ONGs que vinham para a Guiné atraídos pela promessa do renovado socialismo africano esboçado por Amílcar Cabral.

13. O lugar da África no imaginário cabo-verdiano é tema para boas polêmicas. Posiçóes polares, de um jeito ou de outro, são caras às ideologias nacionalistas. Um arquipélago africano ou uma Santiago negra são imagens que gozaram de um favoritismo difuso até os anos 1990. Com o fim do regime do partido único na vida política do país, novas imagens ganharam centralidade. Em Trajano Filho (2005a, 2014c), reflito do exterior sobre o lugar da África na imaginação dos ilhéus.

14. Retomei, sob a forma de reminiscência, o tema da fórmula básica da identidade social em Trajano Filho (1999). Em Trajano Filho (2010b), voltei a refletir sobre a mesma fórmula identitária, desta feita com vistas a propor um modelo explicativo dos lugares como campos comunicativos.

15. Se magra era a bolsa, mais esquelética era a economia brasileira. Os 1.180 dólares que recebia eram usados na manutenção da família, e o que sobrava (e sempre tinha que sobrar) era poupado para fazer a pesquisa.

16. O termo "economia do oculto" ganhou vazão plena na literatura africanista, tanto na acepção sensacionalista de uma antropologia barata e descartável, travestida de duvidoso jornalismo, quanto numa vertente mais ponderada e analiticamente comprometida. Creio eu que, em ambos os casos, o próprio uso do termo, certamente 
com elevado valor de marketing, acaba por retirar algum quantum de seriedade ao olhar. Análises do fenômeno encontram-se em Comaroff e Comaroff $(1999,2002)$ e Ellis e Haar (2004). Perspectiva crítica sobre a proliferação de casos de economia do oculto pode ser encontrada em Ranger (2007). Eu mesmo (Trajano Filho, 1993a, 1993b, 1994, 1995, 2002a, 2004, 2008c), sem fazer uso dessa expressão, me dediquei a analisar alguns casos, todos eles veiculados por vivos rumores. Em minha defesa, tenho a dizer que meu interesse sempre esteve ligado à forma narrativa (os rumores) e nunca ao conteúdo narrado.

17. - Think.

- Thanks!

18. Bantaba, palavra de origem mandinga, significa lugar de reuniáo nas aldeias. Jumbay, termo crioulo de etimologia incerta, refere-se à prática da sociabilidade conversacional. Sobre eles, ver Rougé (1986), Montenegro e Morais (1979) e Trajano Filho (1998).

19. Estas lógicas continuaram a prevalecer nas culturas políticas africanas (Murphy, 2010). Nas feitorias costeiras habitadas por luso-africanos ao norte e ao sul da atual Guiné-Bissau, a ideologia de classificação racial foi se impondo gradualmente. Ao final do século XVIII, as múltiplas identidades situacionais dos descendentes dos lançados (luso-africanos crioulizados) foram dando lugar a identidades fixas, baseadas na cor e na raça. Ver o excelente estudo de Peter Mark (2002) a esse respeito.

20. Ver Trajano Filho (2006b) para uma crítica à noção de resistência no contexto das tabancas de Cabo Verde.

21. As escalas implicacionais usadas para formalizar a existência de contínuos de variação também adentraram a análise antropológica. Ver o trabalho de Goodenough (1965) sobre status e papéis, muito influente na época em que foi publicado, mas hoje lamentavelmente esquecido. Não deixa de ser curioso que o seu autor é um antropólogo com forte pegada linguística.

22. Sobre esse padrão de reciprocidade tâo característico da região, tão central para as estruturas sociais e balizador de um largo sistema de trocas intersocietárias de longa distância, ver Dorjahn e Fyfe (1962), Rodney (1980), Mouser (1980), Brooks (1993), Sarró (2010) e Trajano Filho (1998, 2010a).

23. Nisto, como em quase tudo, estamos diante de uma polêmica, cujas posiçóes polares seriam: (a) os estilos coloniais são fundamentalmente desimportantes para a compreensão das diferenças entre as sociedades coloniais (Fieldhouse, 1966); e (b) as diferenças entre os sistemas inglês e francês de administração são de fundamental importância para compreender as diferenças entre os dois blocos principais linguísticos da África independente (Crowder, 1964). Entre os polos, uma miríade de posições.

24. Novamente, por se tratar de uma ocasiâo de celebração, deixo de detalhar a consciência infeliz que frequentemente assola as atividades de cooperaçáo internacional. Em outra ocasião, eu o fiz com azedume e amargura (Trajano Filho, 2007). 
25. Alcida Ramos (2010), por outros caminhos, chega a conclusão semelhante.

26. De modo muito interessante em suas reflexôes sobre o ensino de pós-graduação em antropologia, Lilia Schwarcz (2006) aponta que algumas linhas de pesquisa tradicionais (ênfase minha) dos programas de pós-graduação não encontram expressão no leque das disciplinas obrigatórias e optativas por eles ofertadas. Ela se pergunta se é o caso de estarem fora de moda ou simplesmente em queda livre. Entre outras, ela destaca África e cultura popular. É essa realidade, bem retratada pela autora, que me faz indagar se estou nadando contra a corrente, se sou um iconoclasta prestes a se tornar herege ou se simplesmente sou um tonto que insiste em fazer apostas erradas. Quem sabe um pouco de tudo isto? (Não posso deixar de notar que me fascinam certas temáticas da antropologia biológica, da arqueologia e da antropologia econômica — outras áreas "em queda livre".)

27. Em Trajano Filho (2012d, 2014b), especulei sobre as causas dessa curiosidade, por isso me abstenho de fazê-lo novamente aqui.

28. Esses são os países em que publiquei os resultados de minhas investigaçôes africanas. Além deles, mantenho vínculos de várias ordens (editoriais, participação em eventos, orientação de estudantes etc.) com México, Argentina, Bélgica, Espanha e Polônia.

29. Escrevo isto sob o impacto da foto revoltante de uma criança morta com o rostinho dentro d'água numa praia do Mediterrâneo. O nome dela é Aylan Kurdi. Nada é mais perverso do que a violência sobre as crianças, esses seres sagrados... Que este memorial seja, também, um ato de memória que não vai me deixar esquecer, que não vai me deixar perdoar.

30. Abstenho-me de passar julgamento ao Qualis das outras áreas, mas suspeito que o quadro não seja muito diferente.

31. Jabuticabas outras, também de natureza institucional, nos distraem e tomam o nosso tempo. Menciono duas: (a) a quase obrigatoriedade do Lattes (não é possível ser pesquisador aqui sem ter esse horrível formato de currículo, e não é possível se internacionalizar só com ele) e (b) a aparente universalização das bolsas de produtividade em pesquisa como instâncias de legitimação (vide a tabela de pontuação deste concurso para professor titular).

32. Mais tarde, em 2003, esses princípios foram aprimorados num texto com minha colega Carla Costa Teixeira, sob a forma de uma proposta para a criação de um curso de graduação em antropologia, com entrada separada em vestibular (Trajano Filho, 2006a). Tal proposta foi aprovada em reuniáo de colegiado, mas, por causa de um tipo de inércia muito comum no mundo acadêmico, não foi implementada. Recentemente, no âmbito de uma reforma curricular mais ampla no Instituto de Ciências Sociais da UnB, a proposta foi retomada e, com pequenas modificaçóes, o bacharelado em antropologia está próximo de ser criado.

33. Como disse o poeta, quem mandou não ler a carta? 
34. Em 1998, usei o termo "protonacionalismo" para qualificar as ações da Liga de modo muito pouco reflexivo. Agora tenho ciência de que tal termo esconde mais do que desvela. Espero que, ao concluir o projeto da Liga, as açóes descritas e analisadas estejam mais bem enquadradas.

35. Está nisto uma reminiscência de meu passado musical sob a forma da tensão entre o rigor formal, classicamente expresso na sonata — uma forma musical congruente e econômica - e o devanear típico do fluxo ininterrupto da consciência, que modernamente ganha expressão na rapsódia - a forma um tanto selvagem e indomada que na modernidade marca a obra de Villa-Lobos.

\section{Referências}

AGHA, Asif. 2007. Language and social relations. Cambridge: Cambridge University Press.

ALENCAR, Rívia Bandeira. 2005. Será que dá samba? Mudança, Gilberto Gil e patrimônio imaterial no Ministério da Cultura. Dissertação de mestrado, Universidade de Brasília.

AMSELLE, Jean-Loup. 1990. Les logiques métisses: anthropologie de l'identité en Afrique et ailleurs. Paris: Payot.

APPADURAI, Arjun. 1986. "Introduction: commodities and the politics of value". In: A. Appaduarai (ed.). The social life of things: commodities in cultural perspective. Cambridge: Cambridge University Press. pp. 3-63.

AUSTIN, John. 1962. How to do things with words. Cambridge, MA: Harvard University Press.

BARBER, Karin. 1997. Readings in African popular culture. Bloomington: Indiana University Press.

BARRY, Boubacar. 1988. La Sénégambie du XV au XIXe siècle: traite négrière, Islam et conquête coloniale. Paris: L'Harmattan.

BASCH, Linda, GLICK SCHILLER, Nina \& BLANC, Cristina Szanton. (eds.). 1994. Nations unbound: transnational projects, postcolonial predicaments and deterritorialized nation-states. Basel: Gordon and Breach.

BICKERTON, Derek. 1973. "On the nature of a Creole continuum". Language, 49:640-669.

BRAZ DIAS, Juliana. 2000. Entre partidas e regressos: tecendo relaçôes familiares em Cabo Verde. Dissertação de mestrado, Universidade de Brasília. 
2004. Mornas e coladeiras de Cabo Verde. Tese de doutorado, Universidade de Brasília.

BRAZ DIAS, Juliana \& LOBO, Andrea de Souza. (orgs.). 2012. África em movimento. Brasília: ABA.

BROOKS, George. E. 1993. Landlords and strangers: ecology, society, and trade in Western Africa, 1000-1630. Boulder: Westview Press.

. 2003. Eurafricans in Western Africa: commerce, socialstatus, gender, and religious observance from the sixteenth to the eighteenth century. Athens, OH: Ohio University Press.

2010. Western Africa and Cabo Verde, 1790s-1830s: symbiosis of slave and legitimate trades. Bloomington: Author House.

BROWN, Penelope \& LEVINSON, Stephen. 1978. "Universals in language usage: politeness phenomena”. In: E. N. Goody (ed.). Questions and politeness: strategies in social interaction. Cambridge: Cambridge University Press. pp. 56-289.

CARREIRA, António. 1972. Cabo Verde: formação e extinção de uma sociedade escravocrata (1460-1878). Bissau: Centro de Estudos da Guiné Portuguesa.

CASTRO, Josué Tomasini. 2009. Atos de memória: as comemoraçôes herero em Okahanja, Namíbia. Dissertação de mestrado, Universidade de Brasília.

. 2013. A política Ovaherero: poder e conflito na Namíbia Central. Tese de doutorado, Universidade de Brasília.

CHABAL, Patrick. 1983. "Party, state, and socialism in Guinea-Bissau". Canadian Journal of African Studies, 17(2):189-210.

CHAUDENSON, Robert. 2001. Creolization of language and culture. London: Routledge.

CLIFFORD, James \& MARCUS, George E. (eds.). 1986. Writing culture: the poetics and politics of ethnography. Berkeley: University of California Press.

COMAROFF, Jean \& COMAROFF, John. 1999. "Alien-nation: zombies, immigrants and millennial capitalism”. Codesria Bulletin, 3-4:17-28.

. 2002. "Occult economies and the violence of abstraction: notes from the South African Postcolony”. American Ethnologist, 26(2):279-303.

COOPER, Frederick. 1994. "Conflict and connection: rethinking colonial African history”. American Historical Review, 19(5):1516-1545. 
COSTA, Patrícia Trindade Maranhão. 2012. As raizes da congada: a renovação do presente pelos filhos do Rosário. Curitiba: Appris.

COUTO, Hildo Honório. 1994. O crioulo português da Guiné-Bissau. Hamburg: Helmut Buske.

CROWDER, Michael. 1964. "Indirect rule: French and British style". Africa, 34(3):197-205.

CURTIN, Philip. 1975. Economic change in precolonial Africa: Senegambia in the era of the slave trade. Madison: The University of Wisconsin Press.

D'AZEVEDO, Warren. 1962. "Some historical problems in the delineation of a Central West Atlantic region”. Annals of the New York Academy of Sciences, 96(2):512-538.

DeCAMP, David. 1971. "Toward a generative analysis of a post-creole speech continuum". In: D. Hymes (ed.). Pidginization and creolization of languages. Cambridge: Cambridge University Press. pp. 349-370.

DORJAHN, V. R. \& FYFE, Christopher. 1962. "Landlord and stranger: change in tenancy relations in Sierra Leone". Journal of African History, 3(3):391-397.

DRUMMOND. Lee. 1980. "The cultural continuum: a theory of intersystem". Man, 15:352-374.

DUARTE, Dulce Almada. 1998. Bilinguismo ou diglossia? Mindelo: Spleen.

DWYER, Kevin. 1982. Moroccan dialogues: anthropology in question. Baltimore: The Johns Hopkins University Press.

ELLIS, Stephen \& HAAR, Gerrie ter. 2004. Worlds of power: religious thought and political practices in Africa. New York: Oxford University Press.

FABIAN, Johannes. 1978. "Popular culture in Africa: findings and conjectures". Africa, 48(4):315-331.

. 1998. Moments of freedom: anthropology and popular culture. Charlottesville: University Press of Virginia.

FELD, Steven. 1982. Sound and sentiment: birds, weeping, poetics, and song in Kaluli expression. Philadelphia: University of Pennsylvania Press.

FIELDHOUSE, David Kenneth. 1966. The colonial empires: a comparative survey from the eighteenth century. New York: A Delta Book.

FRY, Peter. 1976. Spirits of protest: spirit-mediuns and the articulation of consensus among the Zezuru of Southern Rhodesia (Zimbabwe). Cambridge: Cambridge University Press. 
GEERTZ, Clifford. 1973. The interpretation of cultures. New York: Basic Books.

GOFFMAN, Erving. 1967. Interaction ritual: essays on face-to-face behavior. New York: Doubleday Anchor.

. 1974. Frame analysis: an essay on the organization of experience. New York: Harper and Row.

GOODENOUGH, Ward. 1965. "Rethinking status and role: toward a general model of the cultural organization of social relationships". In: M. Banton (ed.). The relevance of models for social anthropology. London: Tavistock. pp. 1-24.

GUMPERZ, J. L. 1982. Discourse strategies. Cambridge: Cambridge University Press.

GUMPERZ, John \& HYMES, Dell. (eds.). 1972. Directions in sociolinguistics: the ethnography of communication. Oxford: Basil Blackwell.

HAIR, Paul Edward Hedley. 1997. Africa encountered: European contacts and evidence 1450-1700. Aldershot: VARIORUM.

HANNERZ, Ulf. 1987. "The world in creolization”. Africa, 57(4):546-559.

1996. Transnational connections: culture, people, places. London: Routledge.

HART, Keith. 1985. "The social anthropology of West Africa”. Annual Review of Anthropology, 14:243-272.

HAVIK, Philip. 2004. Silences and soundbytes: the gendered dynamics of trade and brokerage in pre-colonial Guinea-Bissau region. Münster: LIT Verlag.

HENRY, Christine. 1994. Les îles où dansent les enfants défunts: âge, sexe et pouvoir chez les Bijogo de Guinée-Bissau. Paris: CNRS.

HYMES, Dell. 1964. "Introduction: toward ethnographies of communication". American Anthropologist, 66(6):12-25.

. (ed.) 1971. Pidginization and creolization of languages. Cambridge: Cambridge University Press.

. 1974. Foundations in sociolinguistics: an ethnographic approach. Philadelphia: University of Pennsylvania Press.

KEARNEY, Michael. 1995. "The local and the global: the anthropology of globalization and transnationalism”. Annual Review of Anthropology, 24:547-565.

KIHM, Alain. 1980. "La situation linguistique en Casamance et Guinée-Bissau". Cahiers d'Édudes Africaines, 20(3):369-386. 
KNÖRR, Jacqueline \& TRAJANO FILHO, Wilson. (eds.) 2010. The powerful presence of the past: integration and conflict along the Upper Guinea Coast. Leiden: Brill.

KNÖRR, Jacqueline et al. 2012. "National, ethnic, and creole identities in contemporary upper Guinea coast societies". Max Planck Institute of Social Anthropology Working Papers, 135:1-31.

KOPYTOFF, Igor. 1986. "The cultural biography of things: commoditization as a process". In: A. Appadurai (ed.). The social life of things: commodities in cultural perspective. Cambridge: Cambridge University Press. pp. 65-91.

1987. "The internal African frontier: the making of African political culture". In: I. Kopytoff (ed.), The African Frontier: the reproduction of traditional African societies. Bloomington: Indiana University Press.

LABOV, William. 1972. Language in the Inner City: studies in the Black English Vernacular. Philadelphia: University of Pennsylvania Press. . 1978. Sociolinguistic patterns. Oxford: Basil Blackwell.

LE PAGE, Robert. 1980. "Hugo Schucharddt's creole studies and the problem of linguistic continua”. In: K. Lichem \& H. J. Simon (eds.). Hugo Schuchardt Symposium 1977 in Graz. Wien : Verlag der Osterreichischen Akademie der Wissenschaften. pp. 114-145.

LE PAGE, Robert. \& TABOURET-KELLER, A. 1985. Acts of identity: creole-based approaches to language and ethnicity. Cambridge: Cambridge University Press.

LÉVI-STRAUSS, Claude. 1978. Mito e significado. Lisboa: Ediçôes 70. . 1997. Mythologiques 1: le cru et le cruit. Paris: Plon.

LOBO, Andrea de Souza. 2001. Seca, chuva e luta: reconstruindo a paisagem em Cabo Verde. Dissertação de mestrado, Universidade de Brasília. 2007. Tão longe, tão perto: organização familiar e emigração feminina na ilha de Boa Vista, Cabo Verde. Tese de doutorado, Universidade de Brasília. 2012. Tão longe, tão perto: família e "movimentos" na ilha da Boa Vista de Cabo Verde. Praia: Edições UNICV.

MARCUS, George \& CUSHMAN, Dick. 1982. "Ethnographies as texts". Annual Review of Anthropology, 11:25-69.

MARK, Peter. 1985. A cultural, economic, and religious history of the Basse Casamance since 1500. Stuttgard: Franz Steiner Verlag Wiesbaden. 
2002. "Portuguese" style and Luso-African identity: precolonial Senegambia, sixteenth-nineteenth centuries. Bloomington: Indiana University Press.

MARY, Andre. 1999. Le défi du syncretisme: le travail symbolique de la religion d'Eboga (Gabon). Paris: Éditions de L'École des Hautes Études en Sciences Sociales. . 2000. Le bricolage Africain des héros chrériens. Paris: Les Éditions du CERF.

MBEMBE, Achille. 2001. On the postcolony. Berkeley: University of California Press.

MÉNARD, Anaïs. 2015. Beyond autochthony discourses: Sherbro identity and the (re-) construction of social and national cohesion in Sierra Leone. PhD dissertation, MartinLuther Universität.

MENDY, Peter Karibe. 1994. Colonialismo português em África: a tradição da resistência na Guiné-Bissau (1879-1959). Bissau: Inep.

MIGUEIS, João José de Melo. 1937. Ocupação militar da Guiné. Lisboa: Agência Geral do Ultramar.

MILROY, James. 1992. Linguistic variation \& change. Oxford: Blackwell.

MONTENEGRO, Teresa \& MORAIS, Carlos de. (orgs.). 1979. Junbai. Bolama: Imprensa Nacional.

MOTTA, Antonio, LOBO, Andrea de Souza, \& TRAJANO FILHO, Wilson. (orgs.). 2014. África fora de casa: imagens fora do lugar. Recife: UFPE/ABA.

MOUSER, Bruce. 1980. "Accomodation and assimilation in the landlord-stranger relationship". In: B. K. Swartz Jr. \& R. Dumet (eds.). West African Culture Dynamics. The Hague: Mouton. pp. 495-414.

MUNANGA, Kabengele. 1986. Os Basanga de Shaba: um grupo étnico do Zaire. São Paulo: FFLCH/USP.

MURPHY, Willim. 2010. "Patrimonial logic of centrifugal forces in the political history of the Upper Guinea Coast”. In: J. Knörr \& W. Trajano Filho (eds.). The powerful presence of the past: integration and conflict along the Upper Guinea Coast. Leiden: Brill. pp. 27-54.

NIANE, Djibril Tamsir. 1989. Histoire des mandingues de l'ouest. Paris: Karthala.

ORTNER, Sherry. 1995. "Resistance and the problem of ethnographic refusal". Comparative Studies in Society and History, 37(1):173-193.

PÉLISSIER, René. 1989. História da Guiné: portugueses e africanos na Senegâmbia (18411936), 2 vols. Lisboa: Estampa. 
PÉLISSIER, René. 2006. “AAurora colonialis» e pequenos crepúsculos ulteriores”. Análise Social 180:867-883.

PONTES, Raymundo Ledo. 1912. Documentos e cartas para todos lêrem. Lisboa: Imprensa Africana.

RAMOS, Alcida. 2010. "Revisitando a etnologia brasileira". In: L. F. Duarte (org.). Horizontes das ciências sociais no Brasil: antropologia. Sáo Paulo: Discurso Editorial/ Barcarolla. pp. 25-49.

RANGER, Terence. 2007. "Scotland Yard in the bush: medicine murders, child witches and the construction of the occult: a literature review". Africa, 77(2):272-283.

RICKFORD, John. R. 1987. Dimensions of a creole continuum: history, texts \& linguistic analysis if Guyanese creole. Stanford: Stanford University Press.

. 2002. "Implicational scales". In: J. K. Chambers, P. Trudgill \& N. SchillingEstes (eds.). The handbook of language variation and change. Oxford: Blackwell. pp. 142-167.

ROCHE, C. 1985. Histoire de la Casamance: conquête et résistance, 1850-1920. Paris: Karthala.

RODNEY, Walter. 1970. A history of the upper Guinea coast 1545 to 1800. New York: Monthly Review Press.

ROUGÉ, Jean-Louis. 1986. "Uma hipótese sobre a formação do crioulo da GuinéBissau e da Casamansa”. Soronda (Revista de Estudos Guineenses), 2:28-49.

SAID, Edward. 1985. Beginnings: intention and methods. New York: Columbia University Press.

SANKOFF, Gillian. 1980. "Variation, pidgins and creoles". In: A. Valdman \& A. Highfield (eds.). Theoretical orientations in creole studies. New York: Academic Press. pp. 139-164.

SANSONE, Livio. (org.). 2012. Memórias da África: patrimônios, museus e politicas das identidades. Salvador: EDUFBA/ABA.

SANTOS, Eduardo dos. 1968. O pan-africanismo de ontem e de hoje. Lisboa: Edição do Autor.

SARRÓ, Ramon. 2010. "Map and territory: the politics of place and autochthony among the Baga Sitem (and their neighbours)". In: J. Knörr \& W. Trajano Filho (eds.). The powerful presence of the past: integration and conflict along the Upper Guinea Coast. Leiden: Brill. pp. 231-252. 
SAUTCHUK, João Miguel. 2005. O Brasil em discos: nação, povo e música na produção da gravadora Marcus Pereira. Dissertação de mestrado, Universidade de Brasília.

2009. A poética do improviso: prática e habilidade no repente nordestino. Tese de doutorado, Universidade de Brasília.

. 2012. A poética do improviso: prática e habilidade no repente nordestino. Brasília: Editora Universidade de Brasília.

SCHNEIDER, David. 1968. American kinship. Chicago: The University of Chicago Press.

Press. 1984. A critique of the study of kinship. Ann Arbor: The University of Michigan

SCHOLTE, Bob. 1971. "Discontents in anthropology". Social Research, 38(4):777-807.

SCHWARCZ, Lilia Moritz. 2006. "Ensino de pós-graduação em antropologia: algumas primeiras notas comparativas”. In: M. Grossi, A. Tassinari \& C. Rial (orgs.). Ensino de antropologia no Brasil: formação, práticas disciplinares e além-fronteiras. Florianópolis: Nova Letra. pp. 231-248.

SEARLE, John. 1969. Speech acts: an essay in the philosophy of language. Cambridge: Cambridge University Press.

SERRANO, Carlos. 2008. Angola: nascimento de uma naçāo. Luanda: Kilombelombe.

SILVERSTEIN, Michael. 1976. "Shifters, linguistic categories, and cultural description". In: K. Basso \& E. Selby (eds.). Meaning in anthropology. Albuquerque: University of New Mexico Press. pp. 11-56.

SOUZA LIMA, Antonio Carlos. 1995. Um Grande Cerco de Paz. Poder Tutelar, Indianidade e Formação do Estado No Brasil. 1. ed. Petrópolis: Vozes.

STOLER, Ann Laura \& COOPER, Frederick. 1997. "Between metropole and colony: rethinking a research agenda”. In: F. Cooper \& A. L. Stoler (eds.). Tensions of empire: colonial cultures in a bourgeois world. Berkeley: University of California Press, 1997. pp. 1-58.

TEDLOCK, Dennis. 1983. The spoken world and the work of interpretation. Philadelphia: University of Pennsylvania Press.

TEIXEIRA, António dos Santos. 1917. As perseguiçôes feitas a António dos Santos Teixeira pelo Capitão João Teixeira Pinto. Lisboa: Casa Portuguesa.

TEIXEIRA DA MOTA, Avelino. 1954. A Guiné portuguesa. 2 vols. Lisboa: Agência Geral do Ultramar. 
TEIXEIRA PINTO, João. 1936. A ocupação militar da Guiné. Lisboa: Agência Geral das colónias.

THOMASON, Sarah Grey \& KAUFMAN, Terrence. 1991. Language contact, creolization and genetic linguistics. Berkeley: University of California Press.

TONKIN, Elizabeth. 1990. "West African ethnographic traditions". In: R. Fardon (ed.). Localizing strategies: regional traditions of ethnographic writing. Edinburgh: Scottish Academic Press. pp. 137-151.

TRAJANO FILHO, Wilson. 1977. "Você vê? (para violino e violoncelo)”. Sensus, 1. . 1980. Brasília. Correio Braziliense.

- 1984. Músicos e música no meio da travessia. Dissertação de Mestrado, Universidade de Brasília.

. 1988. "Que barulho é esse, o dos pós-modernos?" Anuário Antropológico, 86:133-151.

. 1993a. "Rumores: uma narrativa da nação". Série Antropologia, 143:1-54.

. 1993b. "A tensão entre a escrita e a oralidade". Soronda (Revista de Estudos Guineenses), 16:73-102.

. 1993c. "O auto de carnaval em São Tomé e Príncipe". Anuário Antropológico, 91:189-220.

. 1993d. "Que barulho é esse, o dos pós-modernos?" Boletim de Informação Sócio-económica, 9(1):41-56.

. 1994. "Invisíveis e liminares: a sociedade crioula e seus heróis". Soronda (Revista de Estudos Guineenses), 18:77-113.

. 1995. "O poder da invisibilidade”. Anuário Antropológico, 93:205-240.

. 1998. Polymorphic creoledom: the "creole" society of Guinea-Bissau. PhD dissertation, University of Pennsylvania.

. 1999. "Da identidade nacional à crioulizaçâo comparada". Humanidades, 47:41-53.

.2001. "Manjuandadis e tabancas: duas formas associativas em duas sociedades crioulas". Artiletra, 36/37:10-11.

. 2002a. "Narratives of national identity in the Web”. Etnográfica, 6(1):141-158.

. 2002b. "Soronda e a produção intelectual no Inep". Soronda, 5:143-177. 
2004. "A constituição de um olhar fragilizado: notas sobre o colonialismo português em África”. In: C. Carvalho \& J. Pina Cabral (orgs.). A persistência da história: passado e contemporaneidade em África. Lisboa: Imprensa de Ciências Sociais. pp. 21-59.

2005a. "A construção da nação e o fim dos projetos crioulos". In: T. Cruz e Silva, M. G. M. Araújo \& C. Cardoso (orgs.). "Lusofonia" em África: história, democracia e integração africana. Dakar: CODESRIA. pp. 95-120.

. 2005b. "A crioulização na Guiné-Bissau: um caso singular". Estudos AfroAsiáticos, 27:57-102.

. 2005c. "Sobre modernidade, tradição e bandeiras". Série Antropologia, 370:1-11.

. 2006a. "Quebrando (ainda que lentamente) a inércia: uma proposta de criação do curso de graduação em antropologia”. In: M. Grossi, A. Tassinari e C. Rial (orgs.). Ensino de antropologia no Brasil: formação, práticas disciplinares e além-fronteiras. Florianópolis: Nova Letra. pp. 281-298.

. 2006b. "Por uma etnografia da resistência: o caso das tabancas de Cabo Verde". Série Antropologia, 408:4-34.

. 2006c. "Campo/contracampo". Etnográfica, (número especial):131-132.

. 2007. "A cooperaçáo internacional e a consciência infeliz: o caso da GuinéBissau”. In: K. C. Silva \& D. S. Simiáo (orgs.). Timor Leste por trás do palco: cooperação internacional e a dialética da formação do Estado. Belo Horizonte: Editora UFMG. pp. 365-382.

. 2008a. "Goffman em África e entre os músicos: reflexôes sobre a influência de sua obra”. Revista Brasileira de Ciências Sociais, 68:167-176.

. 2008b. "O trabalho da crioulização: as práticas de nomeação na Guiné colonial”. Etnográfica, 12(1):95-128.

. 2008c. "O precário equilíbrio entre improvisação e regras: reflexóes sobre a cultura política da Guiné-Bissau”. Revista de Antropologia, 51(1):233-266.

. 2009a. "The conservative aspects of a centripetal diaspora: the case of the Cape Verdean tabancas". África, 79(4):520-542.

. 2009b. "Os cortejos das tabancas: dois modelos da ordem". In: M. L. V. C. Cavalcanti \& J. R. Gonçalves (orgs.). As festas e os dias: ritos e sociabilidades festivas. Rio de Janeiro: ContraCapa. pp. 37-73. 
TRAJANO FILHO, Wilson. 2010a. "The Creole idea of nation and its predicaments: the case of Guinea-Bissau". In J. Knörr \& W. Trajano Filho (eds.). The powerful presence of the past: integration and conflict along the Upper Guinea Coast. Leiden: Brill. pp. 157-183.

2010b. "Introdução". In: W. Trajano Filho (org.). Lugares, pessoas e grupos: as lógicas do pertencimento em perspectiva internacional. Brasília: Athalaia/ABA. pp. 5-24.

. 2010c. Lugares, pessoas e grupos: as lógicas do pertencimento em perspectiva internacional. Brasília: Athalaia/ABA.

2011a. "Dilemas, projetos e questóes: reflexões quase musicais de um antropólogo convertido". In: G. L. Ribeiro, A. M. Fernandes, C. B. Martins \& W. Trajano Filho (orgs.). As ciências sociais no mundo contemporâneo: revisóes e prospecçóes. Brasília: LetrasLivres. pp. 289-300.

. 2011b. "Goffman en Afrique: les cortèges des tabancas et les cadres de l'expérience (Cap-Vert)”. Cahiers d'Études Africaines, 201:193-236.

. 2011c. "La sociabilidad de la diáspora: el retorno". Revista Colombiana de Antropologia, 47(1):155-192.

. 2012a. "Igor Kopytoff, um Elder singular". Cadernos de Campo, 21:229-231.

. 2012b. "As cores nas tabancas: sobre bandeiras e seus usos". In: W. Trajano Filho (org.). Travessias antropológicas: estudos em contextos africanos. Brasília: ABA. pp. 339-366.

. 2012c. "Patrimonialização dos artefatos culturais e a redução dos sentidos". In: L. Sansone (org.). Memórias da África: patrimônios, museus e politicas das identidades. Salvador: EDUFBA/ABA. pp. 11-40.

. 2012d. "Introdução: perspectivas comparativas nos estudos africanos". In: W. Trajano Filho (org.). Travessias antropológicas: estudos em contextos africanos. Brasília: ABA. pp. 7-27.

. 2012e. "A África e o movimento: reflexōes sobre os usos e abusos dos fluxos". In: J. Braz Dias \& A. S. Lobo (orgs.). África em movimento. Brasília: ABA. pp. 23-45. . 2012f. (org.). Travessias antropológicas: estudos em contextos africanos. Brasília: ABA 2014a. "Flutuaçôes semânticas no mundo atlântico". Mana, 20(2):331-353. . 2014b. "Estudos africanos: a experiência com a interdisciplinaridade". O Público e o Privado, 23:21-38. 
2014c. "Dentro e fora de casa: o pendular jogo de imagens da África em Cabo Verde”. In: A. Mota, A. Lobo \& W. Trajano Filho (orgs.). África fora de casa: imagens fora do lugar. Recife: UFPE/ABA. pp. 19-61.

2015. "On Colors and Flags in the Hinterland of Cape Verde's Santiago Island". Mande Studies, 15-16:93-106.

. 2016. "Travelling Terms: Analysis of Semantic Fluctuations in the Atlantic World”. In: J. Knörr \& C. Kohl (eds.). The Upper Guinea Coast in Global Perspective. New York: Berghahn. pp. 157-173.

TRAJANO FILHO, Wilson \& RIBEIRO, Gustavo Lins (orgs.). 2004. O campo da antropologia. Rio de Janeiro: ContraCapa.

TRAJANO FILHO, Wilson, THOMAZ, Omar, BRAZ DIAS, Juliana. \& SILVA, Kelly. 2008. Brazilian anthropologists in Africa: remarks on theory and fieldwork overseas. Vibrant, 5:277-303.

TSUZAKI, Stanley. 1971. "Coexistent systems in language variation: the case of Hawaiian English". In: D. Hymes (ed.). Pidginization and creolization of languages. Cambridge: Cambridge University Press. pp. 327-339.

VASCONCELOS, Loff de. 1916. A defeza das víctimas da Guerra de Bissau: o exterminio da Guiné. Lisboa: Imprensa Libanio da Silva.

VEIGA, Manuel. 2000. Le créole du Cap-Vert: étude gramaticale descriptive et contrastive. Paris: Karthala.

VIGH, Henrik. 2006. Navigating terrains of war: youth and soldiering in Guinea-Bissau. New York: Berghahn Books.

YOUNG, Robert. J. C. 1995. Colonial desire: hybridity in theory, culture and race. London: Routledge. 